\title{
Surveys on Reporting Guideline Usage in Dental Journals
}

\author{
Fang Hua, Tanya Walsh*, Anne-Marie Glenny*, Helen Worthington* \\ Cochrane Oral Health Group, School of Dentistry, The University of Manchester, \\ JR Moore Building, Oxford Rd., Manchester M13 9PL, UK
}

\author{
* Corresponding authors \\ Emails: tanya.walsh@manchester.ac.uk \\ a.glenny@manchester.ac.uk \\ helen.worthington@manchester.ac.uk
}

Keywords: dentistry, editorial policies, peer review, surveys and questionnaires, publishing, periodicals as topic

\section{How to Cite:}

Hua F, Walsh T, Glenny AM, Worthington H. Surveys on Reporting Guideline Usage in Dental Journals. Journal of Dental Research. doi: 10.1177/0022034516657803.

DOI: $10.1177 / 0022034516657803$

PMID: 27384336

Please note that this is a post-print version (after peer-review) for the purpose of self-archiving. Please download the final published version from the publisher's website:

http://jdr.sagepub.com/content/early/2016/07/02/0022034516657803.long 


\section{Abstract}

The objectives of this study were to find out if and how authors and peer reviewers for dental journals are encouraged to use reporting guidelines (RGs), identify factors related to RG endorsement; and to assess the knowledge, opinions and future plans of dental journal Editors-in-Chief (EICs) on RGs.

109 peer-reviewed and original research oriented dental journals that were indexed in the MEDLINE and/or SCIE databases in 2015 were included. The "instructions to authors" and "instructions to reviewers" of these journals were identified and retrieved from journals' official websites. Any mention of RGs or other related policies were sought and extracted. In addition, an anonymous survey of the EICs of included journals was conducted using a validated questionnaire.

All 109 journals provided "instructions to authors", among which 55 (50.5\%) mentioned RGs Only the CONSORT (45.0\%), PRISMA (13.8\%) and STROBE (12.8\%) guidelines were mentioned by more than $10 \%$ of the included journals. Statistical analyses suggest that RGs were more frequently mentioned by SCIE indexed journals $(\mathrm{P}<0.001)$, higher impact journals $(\mathrm{P}=0.002)$ and journals that endorsed the ICMJE (International Committee of Medical Journal Editors) Recommendations $(\mathrm{P}<0.001)$. "Instructions to reviewers" were only available online for 9 journals $(8.3 \%), 3$ of which mentioned RGs. For the EIC survey, the response rate was $32.1 \%$ (35/109). 26 editors (74.3\%) stated that they knew what RGs were before receiving our questionnaire. 24 editors $(68.6 \%)$ believed that RGs should be adopted by all refereed dental journals where appropriate.

RGs are important tools for enhancing research reporting and reducing avoidable research waste. But currently they are not widely endorsed by dental journals. Joint efforts by all stakeholders to further promote RG usage in dentistry are needed. 


\section{Introduction}

The reporting of medical research is critical for the translation of findings into healthcare (Needleman et al. 2008a). However, a variety of reporting deficiencies have been identified in previous methodological reviews of the published literature (Simera et al. 2010). Poor reporting not only hinders the assessment of a study's reliability and applicability, it undermines the available evidence base, and breaches the ethical framework for medical research conduct (Needleman et al. 2008a; Needleman et al. 2008b). Moreover, a recent article suggested that at least 50 percent of research reports in biomedicine were sufficiently poor and therefore unusable, representing an avoidable waste of tens of billions of pounds (Glasziou et al. 2014).

During the past 20 years, methodologists and journal editors have developed many reporting guidelines (RGs). These guidelines detail the essential information required to describe the processes and findings of different types of research studies. Additionally, the EQUATOR Network (Enhancing the QUAlity and Transparency Of health Research) was set up in 2008 to promote responsible reporting of health research, with a focus on wider implementation of RGs (Simera et al. 2010).

Most major medical journals and international editorial groups such as the International Committee of Medical Journal Editors (ICMJE) and the World Association of Medical Editors (WAME) have publicly endorsed RGs and/or the EQUATOR Network (Groves 2008; Hopewell et al. 2008). Such endorsement and relevant active implementation strategies have been shown to be effective in improving health research reporting (Hopewell et al. 2012; Pandis et al. 2014; Turner et al. 2012).

Although many researchers and journal editors have been promoting the use of RGs in the field of dentistry (Giannobile 2015; Needleman et al. 2008b; Pandis and Fedorowicz 2011; Sarkis-Onofre et al. 2015; Turpin 2005), recent studies suggest that the reporting of dental research remains unsatisfactory (Delgado-Ruiz et al. 2015; Gewandter et al. 2015; Hua et al. 2015; Sandhu et al. 2014). To our knowledge, there has been no assessment of dental journal policies or survey of dental journal editors regarding RGs. Such research could provide important insights and facilitate further improvement of dental research reporting.

Therefore, the objectives of the present study were to:

- Find out if and how authors and peer reviewers of dental journals are encouraged to use RGs;

- Identify factors related to dental journals' endorsement of RGs;

- Assess the knowledge, opinions and information needs of dental journal Editors-in-Chief 
(EICs) on RGs; and

- Identify the future plans of dental journal EICs on RG implementation.

\section{Materials and Methods}

\section{Selection of Journals}

In this study, we sought to investigate the relevant editorial policies, and survey the EICs, of main dental journals (indexed in MEDLINE and/or SCIE) that are active, peer-reviewed and original research oriented (Appendix, "Eligibility criteria" and "Search strategy" sections).

\section{Selection of RGs}

In order to ensure the relevance and comprehensiveness of this study, a list of key RGs relevant to dental research was developed a priori. In April 2015, one author (F.H.) identified important and potentially relevant RGs by screening RGs provided in the online RG library of EQUATOR Network. All authors then discussed the appropriateness of each RG and revised the list until consensus was reached. A total of 19 RGs or RG extensions, covering a wide range of study types, were included in the final list (Appendix Table 1).

\section{Survey of Journal Instructions}

For each of the included journals, we retrieved basic information (e.g. impact factor, official website URL, Open Access status) from the NLM Catalog, InCites, Ulrich's Periodicals Directory and DOAJ (Directory of Open Access Journals) websites. Then, during 29 April to 1 May 2015, we screened their official websites for "instruction to authors" and "instruction to reviewers".

From obtained instructions, the following information was extracted by F.H. and independently verified by one of the other authors: 1) whether RGs and the ICMJE Recommendations were mentioned; 2) if mentioned, the level of endorsement and the reference given; 3) related editorial policies, namely word limit, structure of abstracts, trial registration, reporting of funding source, and use of online appendix. Discrepancies were resolved through discussion.

Following previous similar research (Hirst and Altman 2012), mentioning of RGs was broadly defined to include mentioning of:

- A generic term such as "reporting guidelines" or "reporting standards";

- One or more specific reporting guidelines; or 
- The online RG libraries EQUATOR Network and MIBBI (Minimum Information for Biological and Biomedical Investigations) Portal (Taylor et al. 2008).

Endorsement of mentioned RGs and related policies was categorized into (Knuppel et al. 2013; Meerpohl et al. 2011; Meerpohl et al. 2010):

- Recommended: the RG/policy ought to be considered or used (e.g. "should...", "please...", "we recommend/encourage authors/reviewers to..."); and

- Required: the RG/policy is a condition for publication (e.g. "authors must...", "authors are required to...", "we expect authors to...").

\section{Survey of Journal Editors}

On 3 and 4 August 2015, we sent emails to EICs (or the editorial offices, if valid personal email addresses unavailable) of all included journals, inviting them to participate in an anonymous survey by filling out an online questionnaire or its PDF version. The questionnaire was validated (Grindlay et al. 2014), with minor modifications for relevance to dental research. Reminders were sent at three weeks and one week before the closing date (14 September 2015). (Appendix, "Invitation email" and "Questionnaire" sections)

\section{Statistical Analyses}

For the journal instruction survey, descriptive statistics were used to summarize the endorsement of each RG and related policy. Chi-square and nonparametric (Mann-Whitney or Kruskal-Wallis) tests were performed to analyze mentioning of RGs and the number of mentioned specific RGs by journal characteristics, respectively $(\alpha=0.05)$. For the survey of EICs, only descriptive analyses were performed. Themes in responses to open questions were identified and coded by F.H., and then independently verified by one of the other authors. Discrepancies were resolved by discussion.

\section{Results}

\section{Characteristics of Included Journals}

169 unique journals were initially identified in the electronic searches, with 109 remaining after application of eligibility criteria. (Flow diagram see Appendix Figure 1, title of journals see Appendix Table 2, summary of characteristics see Appendix Table 3)

Instructions to Authors 
For all the 109 included journals, "instructions to authors" were available.

Endorsement of the ICMJE Recommendations. 65 journals (59.6\%) mentioned the ICMJE Recommendations. However, among these journals, most (67.7\%) used the title "URM" (Uniform Requirements for Manuscripts submitted to biomedical journals) which is obsolete and thus inappropriate; only 42 journals $(64.6 \%)$ gave the corresponding website URL as reference; and only $39(60.0 \%)$ referred to the content of the manuscript preparation section of ICMJE Recommendations. (Appendix Table 4)

Other editorial policies related to reporting. (Appendix, "Editorial policies" section and Appendix Table 5)

Mentioning of RGs. A total of 55 journals (50.5\%) mentioned RGs. RGs were more frequently mentioned by journals indexed in SCIE $(\mathrm{P}<0.001)$, with higher Impact Factors $(\mathrm{P}=0.002)$, as well as those that endorsed the ICMJE Recommendations $(\mathrm{P}<0.001)$. (Table 1)

Mentioning of online RG libraries. Only $11(10.1 \%)$ and $2(1.8 \%)$ journals mentioned the EQUATOR Network and MIBBI websites, respectively. Among the 11 journals that mentioned the EQUATOR Network, 9 provided the website URL as reference. (Appendix Table 6)

Endorsement of each specific RG. Among the 19 RGs that were deemed important for dental research, 7 were never mentioned. Only CONSORT (45.0\%), PRISMA (13.8\%) and STROBE (12.8\%) were mentioned by more than $10 \%$ of the included journals. Only the adherence to CONSORT (33.9\%) was required by more than $10 \%$ of the included journals. In addition to the 19 pre-specified RGs, 7 journals (6.4\%) mentioned relevant Cochrane Collaboration guidelines as RGs for systematic reviews; 3 journals also mentioned the MIAME (Minimum Information About a Microarray Experiment) guidelines. When a RG was mentioned, most of the time a reference was given and most of the references were the URLs of the corresponding official websites. However, it is worth noting that QUORUM, an obsolete guideline replaced by PRISMA in 2009, was still endorsed by six journals (5.5\%). (Summary see Table 2, details for each journal see Appendix Table 2)

More RGs were mentioned by SCIE indexed journals ( $\mathrm{P}=0.001)$, higher impact journals $(\mathrm{P}=0.01)$, open access journals $(\mathrm{P}=0.034)$, and journals that endorsed the ICMJE 
Recommendations $(\mathrm{P}<0.001)$. (Table 1)

\section{Instructions to Peer Reviewers}

"Instructions to reviewers" were only available online for $9(8.2 \%)$ of the included journals. Only 3 journals mentioned RGs, and 2 of them only used the generic term "reporting guidelines". One journal mentioned the ICMJE Recommendations, EQUATOR Network, MIBBI Portal, and recommended adherence to six specific RGs. (Appendix Table 7, Appendix Table 8)

\section{Survey of Journal Editors}

Thirty-five (32.1\%) of the 109 included journals responded to our survey. 29 responses provided identifying information for the responding editors. Among these, there were 26 EICs, 2 co-editors and 1 managing editor. Given the low response rate, all results need to be treated with caution; it is likely that those responding had greater knowledge/acceptance of RGs.

With regard to knowledge of RGs, 26 editors (74.3\%) knew what RGs were before receiving our questionnaire. Of these, 15 (57.7\%) and 3 (11.5\%) claimed that they were aware of the EQUATOR Network and the MIBBI, respectively. Conference/workshop (26.9\%), medical literature (23.1\%), and experience as an author (19.2\%) were the main sources where editors learned about RGs.

Seventeen editors $(48.6 \%)$ reported that their journals referred to RGs in its instructions to authors, and six of them (35.3\%) had plans to implement additional RGs in the future. Eighteen editors (51.4\%) reported that their journals did not endorse RGs or they did not know whether their journals did. Among these, seven (38.9\%) said they had plans to implement RGs in the future.

In addition, over two-thirds (68.6\%) of responding editors thought that RGs should be adopted by all refereed dental journals where appropriate. Over $50 \%$ of editors believed that the lack of knowledge about RGs was the main factor preventing more widespread adoption of RGs by dental journals. The majority of the respondents (91.4\%) felt it would be useful to have more information of RGs. (Appendix, "Detailed results for the survey of editors" section and Appendix Tables 9 to 17)

\section{Discussion}

$R G$ Endorsement in Instructions to Authors

Complete, accurate and transparent reporting is a moral obligation of all authors of medical 
research. The Declaration of Helsinki states that "researchers ... are accountable for the completeness and accuracy of their reports" (World Medical Association 2013). However, according to a recent survey, many authors are not aware of RGs and the EQUATOR Network (Fuller et al. 2015). Incorporation of RGs and the EQUATOR Network into journals' instructions to authors, combined with explicit requirements of adherence, submission of relevant checklists/flow diagrams, and links to the up-to-date relevant materials have been recommended (Fuller et al. 2015; Hopewell et al. 2008; Simera et al. 2010).

In this study, we found very low endorsement rates of RGs (especially for those other than CONSORT) in dental journals' instructions to authors, which is a finding similar to those of earlier studies undertaken in other medical specialties (Knuppel et al. 2013; Kunath et al. 2012; Meerpohl et al. 2011; Meerpohl et al. 2010). Our results also support the findings that higher impact factor (Kunath et al. 2012), open access publishing (Meerpohl et al. 2011) and mentioning of the ICMJE recommendations (Hopewell et al. 2008) are associated with better RG endorsement. The association between open access publishing and RG endorsement has been attributed to the fact that open access journals are more recent and have sought guidance on recent developments in good publication practice when setting up their instructions (Meerpohl et al. 2011). Positive association between higher impact factor and better research reporting has been found in previous studies (Hua et al. 2015; Peron et al. 2012), but it still remains unclear whether better RG endorsement can lead to a higher impact factor.

In addition, although most journals in this study commendably provided the website URLs when referring to RGs, the inappropriate use of obsolete RG (QUOROM) and guideline title (URM) raised red flags (Tao et al. 2011).

\section{RG Endorsement in Instructions to Reviewers}

Peer review is considered by most researchers to be essential to the communication of biomedical research (Mulligan et al. 2013). However, peer reviewers often fail to detect important reporting deficiencies (Hopewell et al. 2014). In a previous randomized controlled trial, peer review using RGs led to more improvement in reporting than conventional peer review without RGs (Cobo et al. 2011). Therefore, researchers have recommended that journals include RGs and links to relevant checklists/materials (e.g. the EQUATOR website) in their instructions to reviewers, with clear instructions about how to use them (Grindlay 2015; Hirst and Altman 2012; Larson and Cortazal 2012).

In the present study, only 9 dental journals $(8.2 \%)$ provided online instructions to reviewers, and only 3 of them mentioned RGs. In contrast, according to a previous study 
(Hirst and Altman 2012), 35\% of medical journals listed in the "McMaster list" made their instructions to reviewers available online, and nearly half of them mentioned RGs. It is difficult to ascertain how many dental journals send their instructions directly to reviewers, which could include information regarding RGs. Best practice would be to openly publish instruction to reviewers on the journal website, so that authors know how their manuscripts will be reviewed using RGs (Hirst and Altman 2012).

\section{Survey of Journal Editors}

Editors are the "quality gatekeepers" of their journals' content (Simera et al. 2010). Previously, Grindlay et al (2014) surveyed the EICs of veterinary journals using a questionnaire same with ours. Compared to their findings, the results of our survey suggested that dental journal EICs had slightly more knowledge of RGs, implemented RGs more often, and were more willing to receive information regarding RGs. Responses to all open questions were similar to those in Grindlay et al (2014), except that dental journal EICs expressed more considerations on the positive effects of RGs on research ethics and integrity.

Based on the responses to our survey, organizations for dental journal editors (e.g. the American Association of Dental Editors \& Journalists, British Dental Editors Forum) and other academic societies (e.g. the International Association for Dental Research) may play a leading role in tackling the lack of knowledge about RGs, which was considered the main barrier to RG adoption by dental journals. This could be done by disseminating information/materials about RGs via emails and webpages, and organizing training/discussions through dedicated conferences or workshops (Eaton et al. 2015). In addition, since currently most medical editors have little access to formal training, relevant organizations may consider developing tailored training programs and certification for dental journal editors, based on the core competencies for editors, which include thorough knowledge about RGs and how best to implement them (Galipeau et al. 2016; Moher and Altman 2015).

The relevance of different RGs to different dental journals was a common concern among dental journal editors. Some editors recommended the production of a list of RGs relevant to dental journals and standardized texts to be used on journal websites. Several editors also pointed out the importance of collaboration among dental journals. In fact, similar consensus policy has been implemented before by 28 rehabilitation journals which simultaneously started to mandate the use of RGs from January 2015 (Chan et al. 2014). Previously, dental journal editors have collaborated on many issues such as dual submission and plagiarism 
(Hupp et al. 2013), they may consider expanding such collaboration to improve the reporting of dental research and reduce research waste in the field (Glasziou et al. 2014). Editors of major, influential dental journals (Fuller et al. 2015), especially those having successful experience in RG implementation (Pandis et al. 2014), may play a major role in initiating such collaboration.

\section{Recommendations}

Based on our findings, we recommend actions that can be undertaken by authors, peer reviewers, journal editors (including both EICs and editorial board members), dental organizations and institutions to promote the use of RGs, improve research reporting, and thereby reduce research waste in dentistry. (Table 3) Mainly, all stakeholders should familiarize themselves with RGs and relevant resources, and engage in training/education courses/programs regarding RG usage. Journal editors should ensure that their online journal instructions contain adequate information regarding relevant RGs, and develop strategies to actively implement those RGs.

\section{Limitations and strengths}

(Appendix, "Limitations and strengths" section)

\section{Conclusion}

RGs are important tools for enhancing reporting and reducing research waste. However, the results of this study suggest that most RGs are not widely endorsed by dental journals, and there is a lack of relevant knowledge and uniform implementation strategy among dental journal editors. Joint efforts should be made by all stakeholders to further promote the use of RGs and thereby reduce avoidable research waste in the field of dentistry. 


\section{Author Contributions}

F. Hua contributed to conception, design, data acquisition, analysis, interpretation, drafted and critically revised the manuscript; T. Walsh, A.-M. Glenny, H. Worthington contributed to design, data acquisition, analysis, interpretation, critically revised the manuscript. All authors gave final approval and agree to be accountable for all aspects of the work.

\section{Acknowledgements}

We would like to thank Dr. Douglas Grindlay (Centre of Evidence Based Dermatology, University of Nottingham) for his approval to use the questionnaire and for his kind recommendations. We would also like to thank all the Editors-in-Chief who responded to our survey, and the peer reviewers for their helpful comments.

F. Hua is a recipient of the President's Doctoral Scholar Award from The University of Manchester. The funding source had no involvement in the study design, collection, analysis and interpretation of data, preparation of the manuscript, or in the decision to publish. The authors declare no potential conflicts of interest with respect to the authorship and/or publication of this article. 


\section{References}

Chan L, Heinemann AW, Roberts J. 2014. Elevating the quality of disability and rehabilitation research: Mandatory use of the reporting guidelines. Arch Phys Med Rehabil. $95(3): 415-417$.

Cobo E, Cortes J, Ribera JM, Cardellach F, Selva-O'Callaghan A, Kostov B, Garcia L, Cirugeda L, Altman DG, Gonzalez JA et al. 2011. Effect of using reporting guidelines during peer review on quality of final manuscripts submitted to a biomedical journal: Masked randomised trial. BMJ. 343:d6783.

Delgado-Ruiz RA, Calvo Guirado JL, Romanos GE. 2015. Bone grafting materials in critical defects in rabbit calvariae. A systematic review and quality evaluation using arrive guidelines. Clin Oral Implants Res.[accessed $2016 \quad$ March 2015]. http://onlinelibrary.wiley.com/wol2011/doi/2010.1111/clr.12614/full. doi:12610.11111/clr.12614.

Eaton KA, Giannobile WV, Sourgen DL, Balaji SM, Honkala E, Lynch CD. 2015. Improving the quality of papers submitted to dental journals: Transcription of session for editors, associate editors, publishers and others with an interest in scientific publishing held at iadr meeting in cape town on wednesday, 25 june 2014. J Dent. 43(8):855-864.

Fuller T, Pearson M, Peters J, Anderson R. 2015. What affects authors' and editors' use of reporting guidelines? Findings from an online survey and qualitative interviews. PLoS One. 10(4):e0121585.

Galipeau J, Barbour V, Baskin P, Bell-Syer S, Cobey K, Cumpston M, Deeks J, Garner P, MacLehose H, Shamseer L et al. 2016. A scoping review of competencies for scientific editors of biomedical journals. BMC Med. 14:16.

Gewandter JS, Smith SM, McKeown A, Edwards K, Narula A, Pawlowski JR, Rothstein D, Desjardins PJ, Dworkin SF, Gross RA et al. 2015. Reporting of adverse events and statistical details of efficacy estimates in randomized clinical trials of pain in temporomandibular disorders: Analgesic, anesthetic, and addiction clinical trial translations, innovations, opportunities, and networks systematic review. J Am Dent Assoc. 146(4):246-254 e246.

Giannobile WV. 2015. Improving clinical trials in dentistry. J Dent Res. 94(3 Suppl):6S-7S.

Glasziou P, Altman DG, Bossuyt P, Boutron I, Clarke M, Julious S, Michie S, Moher D, Wager E. 2014. Reducing waste from incomplete or unusable reports of biomedical research. Lancet. 383(9913):267-276. 
Grindlay D. 2015. Reporting guidelines: How can they be implemented by veterinary journals? Equine Veterinary Journal. 47(2):133-134.

Grindlay DJ, Dean RS, Christopher MM, Brennan ML. 2014. A survey of the awareness, knowledge, policies and views of veterinary journal editors-in-chief on reporting guidelines for publication of research. BMC Vet Res. 10:10.

Groves T. 2008. Enhancing the quality and transparency of health research. BMJ. 337:a718.

Hirst A, Altman DG. 2012. Are peer reviewers encouraged to use reporting guidelines? A survey of 116 health research journals. PLoS One. 7(4):e35621.

Hopewell S, Altman DG, Moher D, Schulz KF. 2008. Endorsement of the consort statement by high impact factor medical journals: A survey of journal editors and journal 'instructions to authors'. Trials. 9:20.

Hopewell S, Collins GS, Boutron I, Yu LM, Cook J, Shanyinde M, Wharton R, Shamseer L, Altman DG. 2014. Impact of peer review on reports of randomised trials published in open peer review journals: Retrospective before and after study. BMJ. 349:g4145.

Hopewell S, Ravaud P, Baron G, Boutron I. 2012. Effect of editors' implementation of consort guidelines on the reporting of abstracts in high impact medical journals: Interrupted time series analysis. BMJ. 344:e4178.

Hua F, Deng L, Kau CH, Jiang H, He H, Walsh T. 2015. Reporting quality of randomized controlled trial abstracts: Survey of leading general dental journals. J Am Dent Assoc. 146(9):669-678 e661.

Hupp JR, Brennan PA, Lingen MW, Samman N, Wiltfang J. 2013. Journal alliance to address issues of dual submission and plagiarism. J Oral Maxillofac Surg. 71(1):3.

Knuppel H, Metz C, Meerpohl JJ, Strech D. 2013. How psychiatry journals support the unbiased translation of clinical research. A cross-sectional study of editorial policies. PLoS One. 8(10):e75995.

Kunath F, Grobe HR, Rucker G, Engehausen D, Antes G, Wullich B, Meerpohl JJ. 2012. Do journals publishing in the field of urology endorse reporting guidelines? A survey of author instructions. Urol Int. 88(1):54-59.

Larson EL, Cortazal M. 2012. Publication guidelines need widespread adoption. J Clin Epidemiol. 65(3):239-246.

Meerpohl JJ, Wolff RF, Antes G, von Elm E. 2011. Are pediatric open access journals promoting good publication practice? An analysis of author instructions. BMC Pediatr. 11:27.

Meerpohl JJ, Wolff RF, Niemeyer CM, Antes G, von Elm E. 2010. Editorial policies of pediatric 
journals: Survey of instructions for authors. Arch Pediatr Adolesc Med. 164(3):268-272.

Moher D, Altman DG. 2015. Four proposals to help improve the medical research literature. Plos Medicine. 12(9).

Mulligan A, Hall L, Raphael E. 2013. Peer review in a changing world: An international study measuring the attitudes of researchers. Journal of the American Society for Information Science and Technology. 64(1):132-161.

Needleman I, Moher D, Altman DG, Schulz KF, Moles DR, Worthington H. 2008a. Improving the clarity and transparency of reporting health research: A shared obligation and responsibility. J Dent Res. 87(10):894-895.

Needleman I, Worthington H, Moher D, Schulz K, Altman DG. 2008b. Improving the completeness and transparency of reports of randomized trials in oral health: The consort statement. Am J Dent. 21(1):7-12.

Pandis N, Fedorowicz Z. 2011. The international equator network: Enhancing the quality and transparency of health care research. J Appl Oral Sci. 19(5).

Pandis N, Shamseer L, Kokich VG, Fleming PS, Moher D. 2014. Active implementation strategy of consort adherence by a dental specialty journal improved randomized clinical trial reporting. J Clin Epidemiol. 67(9):1044-1048.

Peron J, Pond GR, Gan HK, Chen EX, Almufti R, Maillet D, You B. 2012. Quality of reporting of modern randomized controlled trials in medical oncology: A systematic review. J Natl Cancer Inst. 104(13):982-989.

Sandhu SS, Sandhu J, Kaur H. 2014. Reporting quality of randomized controlled trials in orthodontics-what affects it and did it improve over the last 10 years? Eur J Orthod. 37(4):356-366.

Sarkis-Onofre R, Cenci MS, Demarco FF, Lynch CD, Fleming PS, Pereira-Cenci T, Moher D. 2015. Use of guidelines to improve the quality and transparency of reporting oral health research. Journal of Dentistry. 43(4):397-404.

Simera I, Moher D, Hirst A, Hoey J, Schulz KF, Altman DG. 2010. Transparent and accurate reporting increases reliability, utility, and impact of your research: Reporting guidelines and the equator network. BMC Med. 8:24.

Tao KM, Li XQ, Zhou QH, Moher D, Ling CQ, Yu WF. 2011. From quorom to prisma: A survey of high-impact medical journals' instructions to authors and a review of systematic reviews in anesthesia literature. PLoS One. 6(11):e27611.

Taylor CF, Field D, Sansone SA, Aerts J, Apweiler R, Ashburner M, Ball CA, Binz PA, Bogue M, 
Booth T et al. 2008. Promoting coherent minimum reporting guidelines for biological and biomedical investigations: The mibbi project. Nat Biotechnol. 26(8):889-896.

Turner L, Shamseer L, Altman DG, Weeks L, Peters J, Kober T, Dias S, Schulz KF, Plint AC, Moher D. 2012. Consolidated standards of reporting trials (consort) and the completeness of reporting of randomised controlled trials (rcts) published in medical journals. Cochrane Database Syst Rev. 11:MR000030.

Turpin DL. 2005. Consort and quorom guidelines for reporting randomized clinical trials and systematic reviews. Am J Orthod Dentofacial Orthop. 128(6):681-685; discussion 686.

Declaration of helsinki - ethical principles for medical research involving human subjects. 2013. World Medical Association; [accessed 2016 Mar 5]. http://www.wma.net/en/30publications/10policies/b3/. 
Table 1. Any mention of reporting guidelines (RGs) and the number of specific reporting guidelines endorsed in instructions for authors $(n=109)$.

\begin{tabular}{|c|c|c|c|c|c|c|c|}
\hline \multirow[b]{2}{*}{ Characteristic } & \multirow[b]{2}{*}{ Category } & \multicolumn{4}{|c|}{ Any mention } & \multicolumn{2}{|c|}{ Number of RGs } \\
\hline & & $\mathbf{N}$ & Total & $\%$ & P value $^{a}$ & Median (IQR) & $P_{\text {value }}{ }^{b}$ \\
\hline \multirow[t]{2}{*}{ Type } & General dental journal & 18 & 34 & 52.9 & \multirow{2}{*}{0.837} & $1.0(0.0-1.0)$ & \multirow{2}{*}{0.836} \\
\hline & Specialty dental journal & 37 & 75 & 49.3 & & $0.0(0.0-1.0)$ & \\
\hline \multirow[t]{12}{*}{ Subject } & Dentistry & 18 & 34 & 52.9 & \multirow{12}{*}{0.070} & $1.0(0.0-1.0)$ & \multirow{12}{*}{0.080} \\
\hline & Dental Public Health & 3 & 4 & 75.0 & & $2.5(1.0-3.5)$ & \\
\hline & Endodontics & 4 & 4 & 100.0 & & $2.0(1.0-4.0)$ & \\
\hline & Oral and Maxillofacial & 7 & 9 & 77.8 & & $1.0(0.0-2.0)$ & \\
\hline & Surgery & & & & & & \\
\hline & Orthodontics & 7 & 11 & 63.6 & & $1.0(0.0-2.5)$ & \\
\hline & Paediatric Dentistry & 2 & 7 & 28.6 & & $0.0(0.0-0.5)$ & \\
\hline & Periodontics & 4 & 8 & 50.0 & & $0.5(0.0-2.0)$ & \\
\hline & Prosthodontics & 5 & 10 & 50.0 & & $0.5(0.0-1.0)$ & \\
\hline & Restorative Dentistry & 1 & 4 & 25.0 & & $0.0(0.0-2.5)$ & \\
\hline & Dental Materials & 0 & 3 & 0.0 & & 0.0 (NA) & \\
\hline & Other & 4 & 15 & 26.7 & & $0.0(0.0-0.5)$ & \\
\hline \multirow[t]{2}{*}{ SCIE Indexed } & Yes & 48 & 78 & 61.5 & \multirow{2}{*}{$<0.001$} & $1.0(0.0-2.0)$ & \multirow{2}{*}{0.001} \\
\hline & No & 7 & 31 & 22.6 & & $0.0(0.0-0.0)$ & \\
\hline \multirow[t]{5}{*}{ Impact Factor } & Unavailable & 7 & 31 & 22.6 & \multirow{5}{*}{0.002} & $0.0(0.0-0.0)$ & \multirow{5}{*}{0.010} \\
\hline & $\leq 1$ & 11 & 22 & 50.0 & & $0.0(0.0-1.0)$ & \\
\hline & $1-2$ & 22 & 36 & 61.1 & & $1.0(0.0-2.5)$ & \\
\hline & $2-3$ & 11 & 14 & 78.6 & & $1.0(1.0-2.0)$ & \\
\hline & $\geq 3$ & 4 & 6 & 66.7 & & $1.0(0.0-1.0)$ & \\
\hline \multirow[t]{2}{*}{ Open Access } & Yes & 10 & 14 & 71.4 & \multirow{2}{*}{0.151} & $1.0(0.0-3.0)$ & \multirow{2}{*}{0.034} \\
\hline & No & 45 & 95 & 47.4 & & $0.0(0.0-1.0)$ & \\
\hline ICMJE & Yes & 43 & 65 & 66.2 & \multirow{2}{*}{$<0.001$} & $1.0(0.0-2.0)$ & \multirow{2}{*}{$<0.001$} \\
\hline mentioned & No & 12 & 44 & 27.3 & & $0.0(0.0-1.0)$ & \\
\hline Total & & 55 & 109 & 50.5 & & $0.0(0.0-1.0)$ & \\
\hline
\end{tabular}

$\mathrm{N}$ : number of journals; IQR: interquartile range $\left(25^{\text {th }}\right.$ percentile $-75^{\text {th }}$ percentile); NA: not applicable.

${ }^{a}$ Chi-square tests.

${ }^{\text {b }}$ Kruskal-Wallis tests for Subject and Impact Factor, Mann-Whitney U tests for the rest. 
Table 2. Endorsement of each specific reporting guideline (RG) in instructions for authors $(n=109)$.

\begin{tabular}{|c|c|c|c|c|c|c|c|}
\hline \multirow[b]{2}{*}{ RG } & \multicolumn{2}{|c|}{ Mentioned (\%) } & \multicolumn{3}{|c|}{ Level of Endorsement (\%) } & \multicolumn{2}{|c|}{ Reference (\%) ${ }^{c}$} \\
\hline & No & Yes & $\begin{array}{l}\text { Recom- } \\
\text { mended }\end{array}$ & Required & $\begin{array}{l}\text { Submission } \\
\text { Required }^{\text {b }}\end{array}$ & $\begin{array}{c}\text { Reference } \\
\text { given } \\
\end{array}$ & $\begin{array}{l}\text { Website } \\
\text { URL given }\end{array}$ \\
\hline CONSORT & $60(55.0)$ & $49(45.0)$ & $12(11.0)$ & 37 (33.9) & $33(30.3)$ & $45(91.8)$ & $42(85.7)$ \\
\hline \multicolumn{8}{|l|}{ CONSORT extensions } \\
\hline for abstracts & $104(95.4)$ & $5(4.6)$ & $5(4.6)$ & $0(0.0)$ & $0(0.0)$ & $5(100.0)$ & $5(100.0)$ \\
\hline for CRT & 108 (99.1) & $1(0.9)$ & $1(0.9)$ & $0(0.0)$ & $0(0.0)$ & $1(100.0)$ & $1(100.0)$ \\
\hline $\begin{array}{l}\text { for noninferiority } \\
\text { trials }\end{array}$ & $108(99.1)$ & $1(0.9)$ & $1(0.9)$ & $0(0.0)$ & $0(0.0)$ & $1(100.0)$ & $1(100.0)$ \\
\hline for harms & 109 (100.0) & $0(0.0)$ & $0(0.0)$ & $0(0.0)$ & $0(0.0)$ & -- & -- \\
\hline for PRO & 109 (100.0) & $0(0.0)$ & $0(0.0)$ & $0(0.0)$ & $0(0.0)$ & -- & -- \\
\hline SPIRIT & 108 (99.1) & $1(0.9)$ & $1(0.9)$ & $0(0.0)$ & $0(0.0)$ & $1(100.0)$ & $1(100.0)$ \\
\hline PRISMA & $94(86.2)$ & $15(13.8)$ & $8(7.3)$ & $7(6.4)$ & $4(3.7)$ & $12(80.0)$ & $12(80.0)$ \\
\hline \multicolumn{8}{|l|}{ PRISMA extensions } \\
\hline for abstracts & 109 (100.0) & $0(0.0)$ & $0(0.0)$ & $0(0.0)$ & $0(0.0)$ & -- & -- \\
\hline for protocols & 109 (100.0) & $0(0.0)$ & $0(0.0)$ & $0(0.0)$ & $0(0.0)$ & -- & -- \\
\hline MOOSE & $103(94.5)$ & $6(5.5)$ & $6(5.5)$ & $0(0.0)$ & $0(0.0)$ & $3(50.0)$ & $3(50.0)$ \\
\hline STROBE & $95(87.2)$ & $14(12.8)$ & $11(10.1)$ & $3(2.8)$ & $2(1.8)$ & $10(71.4)$ & $10(71.4)$ \\
\hline STARD & 101 (92.7) & $8(7.3)$ & $7(6.4)$ & $1(0.9)$ & $1(0.9)$ & $6(75.0)$ & $6(75.0)$ \\
\hline CARE & $107(98.2)$ & $2(1.8)$ & $0(0.0)$ & $2(1.8)$ & $2(1.8)$ & $2(100.0)$ & $2(100.0)$ \\
\hline TREND & 108 (99.1) & $1(0.9)$ & $1(0.9)$ & $0(0.0)$ & $0(0.0)$ & $0(0.0)$ & $0(0.0)$ \\
\hline COREQ & 109 (100.0) & $0(0.0)$ & $0(0.0)$ & $0(0.0)$ & $0(0.0)$ & -- & -- \\
\hline ARRIVE & 107 (98.2) & $2(1.8)$ & $0(0.0)$ & $2(1.8)$ & $1(0.9)$ & $2(100.0)$ & $1(50.0)$ \\
\hline STREGA & 109 (100.0) & $0(0.0)$ & $0(0.0)$ & $0(0.0)$ & $0(0.0)$ & -- & -- \\
\hline STROBE-ME & $109(100.0)$ & $0(0.0)$ & $0(0.0)$ & $0(0.0)$ & $0(0.0)$ & -- & -- \\
\hline Cochrane guidelines & 102 (93.6) & $7(6.4)$ & $7(6.4)$ & $0(0.0)$ & $0(0.0)$ & 7 (100.0) & $7(100.0)$ \\
\hline MIAME & 106 (97.2) & $3(2.8)$ & $2(1.8)$ & $1(0.9)$ & $0(0.0)$ & $3(100.0)$ & $3(100.0)$ \\
\hline QUOROM $^{\mathrm{a}}$ & $103(94.5)$ & $6(5.5)$ & $6(5.5)$ & $0(0.0)$ & $0(0.0)$ & $2(33.3)$ & $0(0.0)$ \\
\hline $\begin{array}{l}{ }^{a} \text { Obsolete } g \\
{ }^{b} \text { Both adhe } \\
{ }^{C} \text { The propo } \\
\text { CONSORT: } \\
\text { CRT: cluster } \\
\text { PRO: patien } \\
\text { SPIRIT: Stan } \\
\text { PRISMA: Pre } \\
\text { MOOSE: Me } \\
\text { QUOROM: }\end{array}$ & $\begin{array}{l}\text { dideline replac } \\
\text { ence to the RC } \\
\text { ion among th } \\
\text { ansolidated St } \\
\text { andomised tr } \\
\text {-reported outc } \\
\text { ard Protocol I } \\
\text { a-analysis Of } \\
\text { uality Of Repo }\end{array}$ & $\begin{array}{l}\text { ed by PRISN } \\
\text { and submi } \\
\text { se mentior } \\
\text { indards of } \\
\text { als. } \\
\text { omes. } \\
\text { ems - Reco } \\
\text { it Items for } \\
\text { ting Of Me }\end{array}$ & $\begin{array}{l}\text { endorseme } \\
\text { of releva } \\
\text { the corresp } \\
\text { orting Trials }\end{array}$ & $\begin{array}{l}\text { th of which } \\
\text { t checklists, } \\
\text { onding RG. }\end{array}$ & $\begin{array}{l}\text { onal Trials. } \\
\text { eta-Analyses. }\end{array}$ & quired. & \\
\hline
\end{tabular}


STROBE: Strengthening the Reporting of Observational Studies in Epidemiology.

STARD: STAndards for Reporting of Diagnostic accuracy studies.

CARE: CAse REport.

TREND: Transparent Reporting of Evaluations with Nonrandomized Designs.

COREQ: COnsolidated criteria for REporting Qualitative studies.

ARRIVE: Animal Research - Reporting of In Vivo Experiments.

MIAME: Minimum Information About a Microarray Experiment.

STREGA: STrengthening the REporting of Genetic Association studies.

STROBE-ME: STrengthening the Reporting of OBservational studies in Epidemiology - Molecular Epidemiology. 
Table 3. Recommendations to main stakeholders regarding the use of RGs.

\begin{tabular}{|c|c|}
\hline Stakeholder & Recommendation \\
\hline $\begin{array}{l}\text { Dental journal } \\
\text { editors }\end{array}$ & $\begin{array}{l}\text { - Be familiar with available RGs and relevant resources (e.g. the EQUATOR Network) } \\
\text { - Select robust RGs relevant to the study types accepted by the journal } \\
\text { explicitly require the adherence to the RGs (and submission of relevant } \\
\text { checklists/flow diagrams if appropriate) } \\
\text { - Include these RGs and links to relevant materials in the instructions to peer } \\
\text { reviewers, and state explicitly how reviewers are expected to use RGs } \\
\text { - Make the instructions to authors and instructions to peer reviewers openly } \\
\text { available on the journal's official website } \\
\text { - Consider active implementation strategies such as online videos, annotated sample } \\
\text { article and internal review of the reporting of submitted manuscripts } \\
\text { - Consider working with other dental journal editors to form a consensus policy } \\
\text { across dental journals on the use of RGs } \\
\text { - Consider training peer reviewers regarding assessment of reporting } \\
\text { - Publish editorials introducing the importance of research reporting and use of RGs }\end{array}$ \\
\hline Authors & $\begin{array}{l}\text { - Be familiar with available RGs and relevant resources (e.g. the EQUATOR Network) } \\
\text { - Identify the appropriate RG during the study design stage and register the study as } \\
\text { per the RG } \\
\text { - Write the study report according to the appropriate RG and journals' instructions } \\
\text { - Be responsible for the quality of reports and see RGs as helpful tools rather than } \\
\text { extra burdens }\end{array}$ \\
\hline Peer reviewers & $\begin{array}{l}\text { - Be familiar with available RGs and relevant resources (e.g. the EQUATOR Network) } \\
\text { - Review the manuscripts using journal's instructions and the appropriate RGs, and } \\
\text { point out the reporting deficiencies to authors and editors }\end{array}$ \\
\hline $\begin{array}{l}\text { Organizations } \\
\text { for dental } \\
\text { journal editors }\end{array}$ & $\begin{array}{l}\text { - Disseminate knowledge and materials about RGs to dental journal editors via email } \\
\text { and/or webpages. } \\
\text { - Organize dedicated conferences/workshops for training/communication purposes } \\
\text { - Develop tailored training programs and certification for dental journal editors }\end{array}$ \\
\hline $\begin{array}{l}\text { Dental schools/ } \\
\text { institutions }\end{array}$ & $\begin{array}{l}\text { - Consider incorporating education on good research reporting in existing } \\
\text { courses/programs } \\
\text { - Consider organizing workshops/training on research reporting and peer review for } \\
\text { academic staff }\end{array}$ \\
\hline
\end{tabular}




\section{Surveys on Reporting Guideline Usage in Dental Journals}

\section{Appendix}

\section{Eligibility criteria}

Pre-specified exclusion criteria were: 1) Irrelevant topic: not directly related to human oral health (e.g. veterinary dentistry, forensic dentistry, history of dentistry); 2) Inactive (discontinued); 3) Irregular: not published regularly (e.g. supplements, monographs); 4) Not research oriented: not focused on original research articles (e.g. news, abstracts, summaries, comments); 5) Articles not in English; 6) Website unavailable; and 7) Instructions unavailable.

\section{Search strategy}

The NLM Catalog (www.ncbi.nlm.nih.gov/nlmcatalog) and InCites (via Web of Knowledge) databases were searched for dental journals indexed in MEDLINE (as of 23 March 2015) and/or the "Dentistry, Oral Surgery \& Medicine" category of the 2013 SCIE Journal Citation Report (Thomson Reuters 2014). For the NLM Catalog search, target journals were obtained by searching the subject term "Dentistry[st]" and filtering by "Currently indexed in MEDLINE" and "English".

\section{Editorial policies}

Most of the included journals recommended $(40.4 \%)$ or required $(42.2 \%)$ the reporting of funding sources. However, only $20(18.3 \%)$ recommended and another $20(18.3 \%)$ required trial registration. Only 41 journals (37.6\%) explicitly expressed that they support online publication of appendices. (Appendix Table 5) Most journals (67.9\%) required structured abstracts for original/scientific/research articles. One hundred journals (91.7\%) mentioned explicitly their word limits for abstracts (range: 50 to 500). The word limit for original/scientific/research article abstracts was 250 in 59 journals (59.0\%), 200 in 18 journals (18.0\%), and 300 in 9 journals $(9.0 \%)$.

\section{Detailed results for the survey of editors}

Knowledge of RGs

Twenty-three editors (88.5\%) were aware of the existence of specific RGs for different types of study. However, among the 19 key RGs deemed relevant to dental research, only CONSORT (91.3\%), PRISMA (73.9\%) and STROBE (60.9\%) were known by more than $50 \%$ of these 
editors. (Appendix Table 9, Appendix Table 10)

\section{Current implementation of RGs}

When answering the question "does your journal currently refer to any RGs in its instruction to authors", 17 editors (48.6\%) said "Yes", 15 (42.9\%) said "No", and $3(8.6 \%)$ said they did not know.

According to editors who gave a positive response, eight RGs were referred to in their journals' instructions to authors, with CONSORT (75.0\%), PRISMA (58.8\%) and STROBE (35.3\%) being the most commonly mentioned. (Appendix Table 11) Main reasons for these editors to endorse RGs were to standardize/improve/guide reporting (64.7\%) and improve the quality of submissions/reports (29.4\%). (Appendix Table 12) For manuscripts that do not follow RGs but otherwise satisfy editorial criteria, 15 (88.2\%) of these editors would reject or return them for revision/resubmission, while the other 2 editors $(11.8 \%)$ would publish them anyway.

For those editors who gave a negative response, the main reasons for not endorsing RGs were that their instructions to authors needed updating (53.3\%) and that editors can guide the authors without RGs (26.7\%). (Appendix Table 13)

\section{Future plans regarding RGs}

Among the 17 editors whose journals endorsed RGs, 6 (35.3\%) said their journals had plans to implement additional RGs in the future. More specifically, they wanted to endorse PRISMA, CARE, STARD, CONSORT extensions and the EQUATOR Network, mainly through revision of their journal instructions, for the purposes of better standardization and reporting.

Among 18 editors whose journals did not endorse RGs and those who did not know whether their journals did, 7 (38.9\%) had plans to implement RGs in the future, $2(11.1 \%)$ did not, while the others $(50.0 \%)$ did not know. Most of those who had plans would add CONSORT and PRISMA into their journal instructions, with the objectives of improving quality/standardization and protecting their journals from ethical misconduct.

\section{Opinions on RG implementation}

For the question "do you believe that RGs should be adopted by all refereed dental journals where appropriate", 24 editors $(68.6 \%)$ responded "Yes", $3(8.6 \%)$ responded "No", while 8 (22.9\%) said they did not know. Most (66.7\%) of the 24 supporters of such RG adoption gave the reason that this can improve reporting quality and standardization. (Appendix Table 14) Editors who responded "No" and "Don't know" expressed concerns mainly about the relevance of RGs to different journals' content and readerships, potential impact on the number of 
submissions, as well as the possibility of confusing researchers and readers.

In addition, most editors (53.8\%) believed that "lack of knowledge about RGs" was the main barrier to more widespread adoption of RGs by dental journals. (Appendix Table 15) "More communications about RGs" (20.0\%) and "education/training of all people involved" (20.0\%) were the most commonly considered factors that would promote widespread adoption of RGs by dental journals. (Appendix Table 16)

\section{Information needs}

The majority of the respondents (91.4\%) answered "Yes" to the question "would you find it useful to have more information on RGs". Most of them believed that the best ways to disseminate such information to dental journal editors were through emails (40.6\%), conferences and workshops (15.6\%), online training and materials (15.6\%), as well as organizations for dental journal editors (12.5\%). (Appendix Table 17)

\section{Limitations and strengths}

This study has several limitations. First, despite the use of several email reminders, the response rate in our EIC survey (32.1\%) was relatively low, suggesting that the responses we received may not reflect the opinions of all editors of the included journals. However, this rate is comparable to those in previous surveys (23.3\% to $38.8 \%$ ) of journal editors regarding RGs (Fuller et al. 2015; Grindlay et al. 2014; Hirst and Altman 2012; Hopewell et al. 2008a). Second, the 109 journals included in this study were selected based on the SCIE and MEDLINE databases and thus may not be representative of all dental journals. However, by including journals that were indexed in MEDLINE but not SCIE, our sample was already more comprehensive than those in previous studies regarding editorial policies in dentistry (Faggion 2011; Smail-Faugeron et al. 2015) and other medical specialties (Knuppel et al. 2013; Kunath et al. 2012; Meerpohl et al. 2010). Third, in our survey regarding instructions to reviewers, we did not contact journals' editorial offices to retrieve any instruction disseminated directly to reviewers. But our methodology answers the question of how many dental journals made their instructions to reviewers openly accessible on their websites, which is the best practice (Hirst and Altman 2012), and mimicked the situation in which authors want to read the instruction to reviewers of a journal and know how their manuscripts will be assessed according to relevant RGs. In addition, some of the pre-specified 19 key RGs that we deemed relevant to dental research in general, may be inapplicable to several included journals which had a relatively unique scope. However, since these RGs covered a wide range of study types, from clinical to biological studies, and from quantitative to qualitative research, we argue that for every one of the included journals at least several of the pre-specified RGs were relevant. 
Despite these limitations, our study has several strengths. To our knowledge, it is the first of its kind to: (1) assess the endorsement situation of RGs by dental journals; (2) look at both the instructions to authors and instructions to reviewers; and (3) survey dental journal EICs about their knowledge, opinions, information needs as well as future plans about RGs. In addition, a validated questionnaire (Grindlay et al. 2014) was used for the journal editor survey. The endorsement situation of each RG by each journal was provided (Appendix Table 2), which facilitates future follow-up studies and research on the effectiveness of RG endorsement by dental journals. 


\section{Invitation email}

Dear Editor-in-Chief of (journal title)

To determine the current situation and future trends of dental journals' endorsement of reporting guidelines/standards for research publication, we are carrying out a survey regarding the awareness, knowledge and views of dental journal Editors-in-Chief on reporting guidelines/standards.

An invitation to fill out an online questionnaire is being sent to the Editors-in-Chief of more than one hundred dental journals which are currently indexed in the SCIE or MEDLINE. We would be most grateful if you could spare time from your busy schedule to fill out this short questionnaire.

Please return a single reply as Editor-in-Chief on behalf of your journal, so we receive one response per journal. If there is more than one Editor-in-Chief, please ensure a single response is submitted. The closing date for this survey is Monday 14th September 2015.

You can submit your response anonymously. However, it would help us ascertain the representativeness of the survey results if you provide the identifying information in Section 5 . All information provided will be kept strictly confidential and no individual respondent will be identifiable in the published results. By completing the questionnaire you are indicating your consent to participate in this study.

The findings from this research may be published in peer-reviewed journals and presented at conferences. Summary of findings will be available to participants on request.

* To take the online survey, click on: http://goo.gl/forms/c9GdCs8qW2

* If you cannot open the above web link, you can fill out the attached PDF version of the questionnaire and send it back to us through e-mail.

The questionnaire should take between 10 and 20 minutes to complete. Questions marked with an asterisk require an answer, due to the questionnaire logic. Please note that it is not possible to save and return to your response later.

Thank you in advance for your participation.

Yours sincerely,

Helen Worthington

Anne-Marie Glenny

Tanya Walsh

Fang Hua 
Cochrane Oral Health Group

School of Dentistry

The University of Manchester

J.R. Moore Building

Oxford Road, M13 9PL

UK

If you have any queries or comments about the questionnaire or this survey, please contact: fang.hua@postgrad.manchester.ac.uk

\section{Questionnaire}

Section 1.

This section is about your present knowledge of reporting guidelines/standards.

*1. Before receiving this questionnaire, did you know what a reporting guideline/standard was?

(*Required)

Select one.

Yes (Go to question number 2.)

No (Go to question number 7 .)

2. How and where did you learn about reporting guidelines/standards?

3. Are you aware of the EQUATOR Network and its resources on reporting guidelines/standards? Select one.

Y Yes

No

4. Are you aware of the MIBBI and its resources on reporting guidelines/standards? Select one

$\bigcirc$ Yes

No

*5. Before receiving this questionnaire, were you aware of the existence of separate reporting guidelines/standards for different types of research study? (*Required) 
Select one.
O Yes
(Go to question number 6.)
O No
(Go to question number 7.)

6. Which of the following reporting guidelines/standards were you previously aware of? (Please tick any that apply, or choose "All of the above" or "None of the above")

Select all that apply.

O CONSORT (randomized controlled trials)

O CONSORT for Abstracts

O CONSORT for Harms

O CONSORT for Cluster Randomized Trials

O CONSORT for Patient-Reported Outcomes

$O$ CONSORT for Noninferiority and Equivalence Randomized Trials

O SPIRIT (clinical trial protocols)

O PRISMA (systematic reviews and meta-analyses)

O PRISMA for Abstracts

O PRISMA-P (systematic review and meta-analysis protocols )

O MOOSE (meta-analyses of observational studies in epidemiology)

O STROBE (observational studies-cohort, case-control and cross-sectional)

O CARE (case reports)

O COREQ (qualitative research)

O STARD (diagnostic accuracy studies)

O ARRIVE (research using laboratory animals)

O STREGA (genetic association studies)

O STROBE-ME (molecular epidemiology studies)

$O$ TREND (non-randomized controlled trials)

O None of the above

O All of the above

Section 2.

This section is about current and planned implementation of reporting guidelines/standards by your journal. You might find it helpful to have your journal's "instruction to authors" and "instruction to peer reviewers" at hand. If you are not sure about the answer to any of the questions, we would be grateful if you could obtain the necessary information from your editorial team.

NOTE FOR CLARITY: Reporting guidelines/standards are statements that provide advice on how to report research methods and findings for a particular type of study. They specify a minimum set of items required for a clear and transparent account of what was done and what was found. Examples are CONSORT for randomized controlled trials and PRISMA for systematic reviews and meta-analyses. 
*7. Does your journal currently refer to any reporting guidelines/standards in its instructions to authors? (*Required)

Select one.
O Yes
(Go to question number 8.)
O No
(Go to question number 15.)
O Don't know
(Go to question number 16.)

8. Which reporting guidelines/standards are referred to in the instructions to authors?

9. Why does your journal refer to these reporting guidelines/standards?

10. What does your journal do with submitted studies that do not follow the relevant reporting guideline/standard but otherwise satisfy its editorial criteria?

*11. Does your journal have plans to implement additional reporting guidelines/standards in the future? (*Required)

Select one.

O Yes (Go to question number 12.)

O No (Go to question number 21.)

O All relevant reporting guidelines/standards are already implemented

(Go to question number 21.)

Don't know (Go to question number 21.)

12. Which additional reporting guidelines/standards does your journal plan to implement?

13. What are the reasons for implementing these additional reporting guidelines/standards?

*14. How does your journal plan to implement these additional reporting guidelines/standards?

(*Required)

If answered, go to question number 21. 
*15. What are the reasons why your journal does not refer to reporting guidelines/standards in its instructions to authors? (*Required)

*16. Does your journal have plans to implement reporting guidelines/standards in the future?

(*Required)

Select one.
O Yes
(Go to question number 17.)
O No
(Go to question number 20.)
O Don't know
(Go to question number 21.)

17. Which reporting guidelines/standards does your journal plan to implement?

18. How does your journal plan to implement these reporting guidelines/standards?

*19. What are the reasons for implementing these reporting guidelines/standards? (*Required) If answered, go to question number 21.

*20. What are the reasons why your journal does not plan to implement reporting guidelines/standards in the future? (*Required)

Section 3.

This section is about your views on the potential need for reporting guidelines/standards and their implementation.

21. Do you believe that reporting guidelines/standards should be adopted by all refereed dental journals where appropriate?

Select one.

$\bigcirc$ Yes

No

Don't know 
22. What are the reasons for your answer to the previous question?

23. In your opinion, what factors may be preventing more widespread adoption of reporting guidelines/standards by dental journals?

24. In your opinion, what factors or actions would promote more widespread adoption of reporting guidelines/standards by dental journals?

Section 4.

This section is about information needs.

25. Would you find it useful to have more information on reporting guidelines/standards?

Select one.

Yes

No

26. What would be the best way(s) to disseminate such information to dental journal editors?

27. Do you have any further comments you would like to make about reporting guidelines/standards or about this survey?

Section 5.

This optional section is about your journal and about you. You do not need to answer any of these questions. However, information provided would be helpful for us to ascertain the representativeness of the survey results. If you provide your contact details, the information will be kept confidential. All results will be presented in an anonymized manner.

28. OPTIONAL: What country is your journal officially published in? 
29. OPTIONAL: The name of your journal

30. OPTIONAL: Your official role/job title in the journal

31. OPTIONAL: Your name

32. OPTIONAL: Your e-mail address-if you are interested in more about reporting guidelines.

\section{Thank you for your participation in this survey!}

For further information about reporting guidelines and standards see the EQUATOR Network (www.equator-network.org) and MIBBI (www.biosharing.org/standards/mibbi) websites.

This questionnaire was modified from the questionnaire used in a previous study in veterinary medicine (Grindlay, 2014) with the original authors' approval.

If you wish to find out more about why we are doing this questionnaire, or have any queries about the questions, please contact Mr. Fang Hua at the address below.

Cochrane Oral Health Group

School of Dentistry

The University of Manchester

J.R. Moore Building

Oxford Road, M13 9PL

UK

E-mail: fang.hua@postgrad.manchester.ac.uk 
Appendix Table 1. Key reporting guidelines (RGs) relevant to dental research.

\begin{tabular}{|c|c|c|}
\hline No. & RGs & Publication \\
\hline \multirow[t]{2}{*}{1} & CONSORT (Consolidated Standards of Reporting Trials) & (Moher et al. 2010) \\
\hline & CONSORT extensions & \\
\hline 2 & for abstracts & $\begin{array}{l}\text { (Hopewell et al. } \\
\text { 2008b) }\end{array}$ \\
\hline 3 & for cluster randomized trials & (Campbell et al. 2012) \\
\hline 4 & for noninferiority and equivalence randomized trials & (Piaggio et al. 2012) \\
\hline 5 & for harms & (loannidis et al. 2004) \\
\hline 6 & for patient-reported outcomes & (Calvert et al. 2013) \\
\hline 7 & SPIRIT (Standard Protocol Items - Recommendations for Interventional Trials) & (Chan et al. 2013) \\
\hline \multirow[t]{2}{*}{8} & PRISMA (Preferred Reporting Items for Systematic Reviews and Meta-Analyses) & (Moher et al. 2009) \\
\hline & PRISMA extensions & \\
\hline 9 & for abstracts & (Beller et al. 2013) \\
\hline 10 & for protocols & (Shamseer et al. 2015) \\
\hline 11 & MOOSE (Meta-analysis Of Observational Studies in Epidemiology) & (Stroup et al. 2000) \\
\hline 12 & STROBE (Strengthening the Reporting of Observational Studies in Epidemiology) & $\begin{array}{l}\text { (Vandenbroucke et al. } \\
\text { 2007) }\end{array}$ \\
\hline 13 & STARD (STAndards for Reporting of Diagnostic accuracy studies) & (Bossuyt et al. 2015) \\
\hline 14 & CARE (CAse REport) & (Gagnier et al. 2014) \\
\hline 15 & TREND (Transparent Reporting of Evaluations with Nonrandomized Designs) & $\begin{array}{c}\text { (Des Jarlais et al. } \\
\text { 2004) }\end{array}$ \\
\hline 16 & COREQ (COnsolidated criteria for REporting Qualitative studies) & (Tong et al. 2007) \\
\hline 17 & ARRIVE (Animal Research - Reporting of In Vivo Experiments) & (Kilkenny et al. 2010) \\
\hline 18 & STREGA (STrengthening the REporting of Genetic Association studies) & (Little et al. 2009) \\
\hline 19 & $\begin{array}{l}\text { STROBE-ME (STrengthening the Reporting of OBservational studies in } \\
\text { Epidemiology-Molecular Epidemiology) }\end{array}$ & (Gallo et al. 2011) \\
\hline
\end{tabular}


Appendix Table 2. Journals included in this study and endorsement of EQUATOR Network, MIBBI and each of the 19 key RGs in their instructions to authors (as of May 2015).

\begin{tabular}{|c|c|c|c|c|c|c|c|c|c|c|c|c|c|c|c|c|c|c|c|c|c|c|}
\hline \multirow{2}{*}{$\begin{array}{c}\text { Journal } \\
\text { No. }\end{array}$} & \multirow[t]{2}{*}{ Journal Title } & \multirow[t]{2}{*}{$\mathrm{EN}^{\mathrm{a}}$} & \multirow[t]{2}{*}{$M P^{b}$} & \multicolumn{19}{|c|}{ RG No. ${ }^{c}$} \\
\hline & & & & 1 & 2 & 3 & 4 & 5 & 6 & 7 & 8 & 9 & 10 & 11 & 12 & 13 & 14 & 15 & 16 & 17 & 18 & $1 \mathrm{~S}$ \\
\hline 1 & Acta Odontol Latinoam & & & & & & & & & & & & & & & & & & & & & \\
\hline 2 & Acta Odontol Scand & & & & & & & & & & & & & & & & & & & & & \\
\hline 3 & Am J Dent & & & $\alpha$ & & & & & & & & & & & & & & & & & & \\
\hline \multirow[t]{2}{*}{4} & Am J Orthod Dentofacial & & & $\gamma$ & $\alpha$ & $\alpha$ & $\alpha$ & & & & $\gamma$ & & & & & & & & & & & \\
\hline & Orthop & & & & & & & & & & & & & & & & & & & & & \\
\hline 5 & Anesth Prog & & & & & & & & & & & & & & & & & & & & & \\
\hline 6 & Angle Orthod & & & & & & & & & & $\alpha$ & & & & & & & & & & & \\
\hline 7 & Arch Oral Biol & & & & & & & & & & & & & & & & & & & & & \\
\hline 8 & Aust Dent J & $\sqrt{ }$ & & $\alpha$ & & & & & & & & & & $\alpha$ & $\alpha$ & $\alpha$ & & & & & & \\
\hline 9 & Aust Endod J & $\sqrt{ }$ & & $\alpha$ & & & & & & & & & & $\alpha$ & $\alpha$ & $\alpha$ & & & & & & \\
\hline 10 & Aust Orthod J & & & & & & & & & & & & & & & & & & & & & \\
\hline 11 & BMC Oral Health & $\sqrt{ }$ & $\sqrt{ }$ & $\alpha$ & $\alpha$ & & & & & $\alpha$ & $\alpha$ & & & $\alpha$ & $\alpha$ & $\alpha$ & $\gamma$ & & & & & \\
\hline 12 & Br Dent J & & & $\beta$ & & & & & & & $\beta$ & & & & & & & & & $\beta$ & & \\
\hline 13 & Br J Oral Maxillofac Surg & & & $\gamma$ & & & & & & & & & & & & & & & & & & \\
\hline 14 & Braz Dent J & & & & & & & & & & & & & & & & & & & & & \\
\hline 15 & Braz Oral Res & & & $\gamma$ & & & & & & & & & & & & & & & & & & \\
\hline 16 & Bull Tokyo Dent Coll & & & & & & & & & & & & & & & & & & & & & \\
\hline 17 & Caries Res & & & $\gamma$ & & & & & & & & & & & & & & & & & & \\
\hline 18 & Chin J Dent Res & & & & & & & & & & & & & & & & & & & & & \\
\hline 19 & Cleft Palate Craniofac J & & & & & & & & & & & & & & & & & & & & & \\
\hline 20 & Clin Implant Dent Relat & & & $\gamma$ & & & & & & & & & & & & & & & & & & \\
\hline & Res & & & & & & & & & & & & & & & & & & & & & \\
\hline
\end{tabular}


Appendix Table 2. (continued)

\begin{tabular}{|c|c|c|c|c|c|c|c|c|c|c|c|c|c|c|c|c|c|c|c|c|c|c|}
\hline \multirow{2}{*}{$\begin{array}{c}\text { Journal } \\
\text { No. }\end{array}$} & \multirow[t]{2}{*}{ Journal Title } & \multirow[t]{2}{*}{$\mathrm{EN}^{\mathrm{a}}$} & \multirow[t]{2}{*}{$M P^{b}$} & \multicolumn{19}{|c|}{ RG No. ${ }^{c}$} \\
\hline & & & & 1 & 2 & 3 & 4 & 5 & 6 & 7 & 8 & 9 & 10 & 11 & 12 & 13 & 14 & 15 & 16 & 17 & 18 & $1 \mathrm{c}$ \\
\hline 21 & Clin Oral Implants Res & & & $\nu$ & & & & & & & & & & & & & & & & & & \\
\hline 22 & Clin Oral Investig & & & & & & & & & & & & & & & & & & & & & \\
\hline 23 & Community Dent Health & & & $\alpha$ & & & & & & & & & & & $\alpha$ & & & & & & & \\
\hline 24 & $\begin{array}{l}\text { Community Dent Oral } \\
\text { Epidemiol }\end{array}$ & $\sqrt{ }$ & & $\gamma$ & & & & & & & & & & $\alpha$ & $\alpha$ & & & & & & & \\
\hline 25 & Cranio & $\sqrt{ }$ & & & & & & & & & & & & & & & & & & & & \\
\hline 26 & Dent Mater & & & & & & & & & & & & & & & & & & & & & \\
\hline 27 & Dent Mater J & & & & & & & & & & & & & & & & & & & & & \\
\hline 28 & Dent Traumatol & & & $\gamma$ & & & & & & & & & & & & & & & & & & \\
\hline 29 & Dentomaxillofac Radiol & & & & & & & & & & & & & & & & & & & & & \\
\hline 30 & Eur Arch Paediatr Dent & & & & & & & & & & & & & & & & & & & & & \\
\hline 31 & Eur J Dent Educ & & & & & & & & & & & & & & & & & & & & & \\
\hline 32 & Eur J Oral Implantol & $\sqrt{ }$ & & $\alpha$ & & & & & & & $\alpha$ & & & & $\alpha$ & $\alpha$ & & & & & & \\
\hline 33 & Eur J Oral Sci & & & $\gamma$ & & & & & & & & & & & & & & & & & & \\
\hline 34 & Eur J Orthod & & & $\gamma$ & $\alpha$ & & & & & & $\gamma$ & & & & & & & & & & & \\
\hline 35 & Eur J Paediatr Dent & & & & & & & & & & & & & & & & & & & & & \\
\hline 36 & $\begin{array}{l}\text { Eur J Prosthodont Restor } \\
\text { Dent }\end{array}$ & & & $\alpha$ & & & & & & & & & & $\alpha$ & $\alpha$ & $\alpha$ & & & & & & \\
\hline 37 & Gen Dent & & & & & & & & & & & & & & & & & & & & & \\
\hline 38 & Gerodontology & & & & & & & & & & & & & & & & & & & & & \\
\hline 39 & Head Face Med & & & & $\alpha$ & & & & & & & & & & & & $\gamma$ & & & & & \\
\hline 40 & Implant Dent & & & & & & & & & & & & & & & & & & & & & \\
\hline
\end{tabular}


Appendix Table 2. (continued)

\begin{tabular}{|c|c|c|c|c|c|c|c|c|c|c|c|c|c|c|c|c|c|c|c|c|c|c|}
\hline \multirow{2}{*}{$\begin{array}{c}\text { Journal } \\
\text { No. }\end{array}$} & \multirow[t]{2}{*}{ Journal Title } & \multirow[t]{2}{*}{$\mathrm{EN}^{\mathrm{a}}$} & \multirow[t]{2}{*}{$\mathrm{MP}^{\mathrm{b}}$} & \multicolumn{19}{|c|}{ RG No. ${ }^{c}$} \\
\hline & & & & 1 & 2 & 3 & 4 & 5 & 6 & 7 & 8 & 9 & 10 & 11 & 12 & 13 & 14 & 15 & 16 & 17 & 18 & 15 \\
\hline 41 & Indian J Dent Res & & & $\alpha$ & & & & & & & $\alpha$ & & & & & & & & & & & \\
\hline 42 & Int Dent J & & & 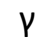 & & & & & & & & & & & & & & & & & & \\
\hline 43 & Int Endod J & & & 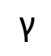 & & & & & & & $\gamma$ & & & & & & & & & & & \\
\hline 44 & Int J Comput Dent & & & & & & & & & & & & & & & & & & & & & \\
\hline 45 & Int J Dent Hyg & $\sqrt{ }$ & & $v$ & & & & & & & $\alpha$ & & & & $\alpha$ & & & $\alpha$ & & & & \\
\hline 46 & Int J Esthet Dent & & & & & & & & & & & & & & & & & & & & & \\
\hline 47 & Int J Oral Maxillofac & & & & & & & & & & & & & & & & & & & & & \\
\hline & Implants & & & & & & & & & & & & & & & & & & & & & \\
\hline 48 & Int J Oral Maxillofac Surg & & & $\beta$ & & & & & & & $\beta$ & & & & $\beta$ & & & & & & & \\
\hline 49 & Int J Oral Sci & & & & & & & & & & & & & & & & & & & & & \\
\hline 50 & Int J Orthod Milwaukee & & & & & & & & & & & & & & & & & & & & & \\
\hline 51 & Int J Paediatr Dent & & & 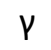 & & & & & & & & & & & & & & & & & & \\
\hline 52 & Int J Periodontics & & & & & & & & & & & & & & & & & & & & & \\
\hline & Restorative Dent & & & & & & & & & & & & & & & & & & & & & \\
\hline 53 & Int J Prosthodont & & & & & & & & & & & & & & & & & & & & & \\
\hline 54 & J Adhes Dent & & & & & & & & & & & & & & & & & & & & & \\
\hline 55 & J Am Dent Assoc & & & $\beta$ & & & & & & & $\beta$ & & & & & & & & & & & \\
\hline 56 & J Appl Oral Sci & & & v & & & & & & & & & & & & & & & & & & \\
\hline 57 & J Can Dent Assoc & & & $\alpha$ & & & & & & & & & & & & & & & & & & \\
\hline 58 & J Clin Dent & & & & & & & & & & & & & & & & & & & & & \\
\hline 59 & J Clin Orthod & & & & & & & & & & & & & & & & & & & & & \\
\hline 60 & J Clin Pediatr Dent & & & & & & & & & & & & & & & & & & & & & \\
\hline
\end{tabular}


Appendix Table 2. (continued)

\begin{tabular}{|c|c|c|c|c|c|c|c|c|c|c|c|c|c|c|c|c|c|c|c|c|c|c|}
\hline \multirow{2}{*}{$\begin{array}{c}\text { Journal } \\
\text { No. }\end{array}$} & \multirow[t]{2}{*}{ Journal Title } & \multirow[t]{2}{*}{$\mathrm{EN}^{\mathrm{a}}$} & \multirow[t]{2}{*}{$M P^{b}$} & \multicolumn{19}{|c|}{ RG No. ${ }^{c}$} \\
\hline & & & & 1 & 2 & 3 & 4 & 5 & 6 & 7 & 8 & 9 & 10 & 11 & 12 & 13 & 14 & 15 & 16 & 17 & 18 & $1 \mathrm{c}$ \\
\hline 61 & J Clin Periodontol & & & $\gamma$ & & & & & & & & & & & & & & & & & & \\
\hline 62 & J Contemp Dent Pract & & & & & & & & & & & & & & & & & & & & & \\
\hline 63 & J Craniomaxillofac Surg & & & $\gamma$ & & & & & & & & & & & & & & & & & & \\
\hline 64 & J Dent & & & $\gamma$ & & & & & & & & & & & & & & & & & & \\
\hline 65 & J Dent Child (Chic) & & & & & & & & & & & & & & & & & & & & & \\
\hline 66 & J Dent Educ & & & & & & & & & & $\alpha$ & & & & & & & & & & & \\
\hline 67 & J Dent Hyg & & & & & & & & & & & & & & & & & & & & & \\
\hline 68 & J Dent Res & $\sqrt{ }$ & & $\gamma$ & & & & & & & & & & & $\gamma$ & & & & & $\gamma$ & & \\
\hline 69 & J Dent Sci & & & $\nu$ & & & & & & & & & & & & & & & & & & \\
\hline 70 & $J$ Endod & & & $\nu$ & & & & & & & & & & & & & & & & & & \\
\hline 71 & J Esthet Restor Dent & & & & & & & & & & & & & & & & & & & & & \\
\hline 72 & J Indian Soc Pedod Prev & & & $\alpha$ & & & & & & & & & & & & & & & & & & \\
\hline & Dent & & & & & & & & & & & & & & & & & & & & & \\
\hline 73 & $\mathrm{~J}$ Int Acad Periodontol & & & & & & & & & & & & & & & & & & & & & \\
\hline 74 & J Investig Clin Dent & & & $\nu$ & & & & & & & & & & & & & & & & & & \\
\hline 75 & J Oral Facial Pain & & & & & & & & & & & & & & & & & & & & & \\
\hline & Headache & & & & & & & & & & & & & & & & & & & & & \\
\hline 76 & J Oral Implantol & & & & & & & & & & & & & & & & & & & & & \\
\hline 77 & J Oral Maxillofac Surg & & & $\beta$ & & & & & & & & & & & $\alpha$ & & & & & & & \\
\hline 78 & J Oral Pathol Med & & & $\gamma$ & & & & & & & & & & & & & & & & & & \\
\hline 79 & J Oral Rehabil & $\sqrt{ }$ & & $\gamma$ & & & & & & & $\gamma$ & & & & $\gamma$ & $\gamma$ & & & & & & \\
\hline 80 & J Oral Sci & & & & & & & & & & & & & & & & & & & & & \\
\hline
\end{tabular}


Appendix Table 2. (continued)

\begin{tabular}{|c|c|c|c|c|c|c|c|c|c|c|c|c|c|c|c|c|c|c|c|c|c|c|}
\hline \multirow{2}{*}{$\begin{array}{c}\text { Journal } \\
\text { No. }\end{array}$} & \multirow[t]{2}{*}{ Journal Title } & \multirow[t]{2}{*}{$\mathrm{EN}^{\mathrm{a}}$} & \multirow[t]{2}{*}{$\mathrm{MP}^{\mathrm{b}}$} & \multicolumn{19}{|c|}{ RG No. ${ }^{c}$} \\
\hline & & & & 1 & 2 & 3 & 4 & 5 & 6 & 7 & 8 & 9 & 10 & 11 & 12 & 13 & 14 & 15 & 16 & 17 & 18 & 1s \\
\hline 81 & J Orofac Orthop & & & $\alpha$ & & & & & & & & & & & & & & & & & & \\
\hline 82 & J Orthod & $\sqrt{ }$ & & $\gamma$ & & & & & & & $\alpha$ & & & & & & & & & & & \\
\hline 83 & J Periodontal Res & & & $\gamma$ & & & & & & & & & & & & & & & & & & \\
\hline 84 & J Periodontol & & & $\gamma$ & & & & & & & & & & & & & & & & & & \\
\hline 85 & J Prosthet Dent & & & & & & & & & & & & & & & & & & & & & \\
\hline 86 & J Prosthodont & & & & & & & & & & & & & & & & & & & & & \\
\hline 87 & J Prosthodont Res & & & v & & & & & & & & & & & & & & & & & & \\
\hline 88 & J Public Health Dent & & & 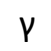 & & & & & & & & & & & $\alpha$ & & & & & & & \\
\hline 89 & Korean J Orthod & & & & & & & & & & & & & & & & & & & & & \\
\hline \multirow[t]{2}{*}{90} & Med Oral Patol Oral Cir & & & & & & & & & & & & & & & & & & & & & \\
\hline & Bucal & & & & & & & & & & & & & & & & & & & & & \\
\hline 91 & Mol Oral Microbiol & & & & & & & & & & & & & & & & & & & & & \\
\hline 92 & Odontology & & & & & & & & & & & & & & & & & & & & & \\
\hline 93 & Oper Dent & & & & & & & & & & & & & & & & & & & & & \\
\hline 94 & Oral Dis & & & Y & & & & & & & & & & & & & & & & & & \\
\hline 95 & Oral Health Prev Dent & & & & & & & & & & & & & & & & & & & & & \\
\hline 96 & Oral Maxillofac Surg & & & & & & & & & & & & & & & & & & & & & \\
\hline 97 & Oral Oncol & & & $\gamma$ & & & & & & & & & & & & & & & & & & \\
\hline 98 & Oral Radiol & & & & & & & & & & & & & & & & & & & & & \\
\hline \multirow[t]{2}{*}{99} & Oral Surg Oral Med Oral & & & & & & & & & & & & & & & $\alpha$ & & & & & & \\
\hline & Pathol Oral & & & & & & & & & & & & & & & & & & & & & \\
\hline 100 & Orthod Craniofac Res & & & $\gamma$ & & & & & & & & & & & & & & & & & & \\
\hline
\end{tabular}


Appendix Table 2. (continued)

\begin{tabular}{|c|c|c|c|c|c|c|c|c|c|c|c|c|c|c|c|c|c|c|c|c|c|c|}
\hline \multirow{2}{*}{$\begin{array}{c}\text { Journal } \\
\text { No. }\end{array}$} & \multirow[t]{2}{*}{ Journal Title } & \multirow[t]{2}{*}{$\mathrm{EN}^{\mathrm{a}}$} & \multirow[t]{2}{*}{$\mathrm{MP}^{\mathrm{b}}$} & \multicolumn{19}{|c|}{ RG No. ${ }^{c}$} \\
\hline & & & & 1 & 2 & 3 & 4 & 5 & 6 & 7 & 8 & 9 & 10 & 11 & 12 & 13 & 14 & 15 & 16 & 17 & 18 & $1 \subseteq$ \\
\hline 101 & Pediatr Dent & & & & & & & & & & & & & & & & & & & & & \\
\hline 102 & Periodontol 2000 & & & & & & & & & & & & & & & & & & & & & \\
\hline 103 & Prog Orthod & $\sqrt{ }$ & $\sqrt{ }$ & $\alpha$ & $\alpha$ & & & & & & $\alpha$ & & & $\alpha$ & $\alpha$ & $\alpha$ & & & & & & \\
\hline 104 & Quintessence Int & & & $\gamma$ & & & & & & & & & & & & & & & & & & \\
\hline 105 & SAAD Dig & & & & & & & & & & & & & & & & & & & & & \\
\hline 106 & SADJ & & & & & & & & & & & & & & & & & & & & & \\
\hline 107 & Singapore Dent J & & & & & & & & & & & & & & & & & & & & & \\
\hline 108 & Spec Care Dentist & & & & & & & & & & & & & & & & & & & & & \\
\hline 109 & Stomatologija & & & & & & & & & & & & & & & & & & & & & \\
\hline
\end{tabular}


Appendix Table 3. Characteristics of included journals.

\begin{tabular}{|c|c|c|c|}
\hline Characteristic & Category & $\mathbf{N}$ & $\%$ \\
\hline \multirow[t]{2}{*}{ Type } & General dental journal & 34 & 31.2 \\
\hline & Specialty dental journal & 75 & 68.8 \\
\hline \multirow[t]{11}{*}{ Subject } & Dentistry & 34 & 31.2 \\
\hline & Dental Public Health & 4 & 3.7 \\
\hline & Endodontics & 4 & 3.7 \\
\hline & Oral and Maxillofacial Surgery & 9 & 8.3 \\
\hline & Orthodontics & 11 & 10.1 \\
\hline & Paediatric Dentistry & 7 & 6.4 \\
\hline & Periodontics & 8 & 7.3 \\
\hline & Prosthodontics & 10 & 9.2 \\
\hline & Restorative Dentistry & 4 & 3.7 \\
\hline & Dental Materials & 3 & 2.8 \\
\hline & Other & 15 & 13.8 \\
\hline \multirow[t]{2}{*}{ SCIE Indexed } & Yes & 78 & 71.6 \\
\hline & No & 31 & 28.4 \\
\hline \multirow[t]{5}{*}{ Impact Factor } & Unavailable & 31 & 28.4 \\
\hline & $\leq 1$ & 22 & 20.2 \\
\hline & $1-2$ & 36 & 33.0 \\
\hline & $2-3$ & 14 & 12.8 \\
\hline & $\geq 3$ & 6 & 5.5 \\
\hline \multirow[t]{2}{*}{ Open Access } & Yes & 14 & 12.8 \\
\hline & No & 95 & 87.2 \\
\hline Total & & 109 & 100 \\
\hline
\end{tabular}

$\mathrm{N}$ : number of journals. 
Appendix Table 4. Endorsement of the ICMJE Recommendations in instructions for authors ( $n=109)$.

\begin{tabular}{lcc}
\hline & N & $\%$ \\
\hline Not mentioned & 44 & 40.4 \\
Mentioned & 65 & 59.6 \\
Inappropriate title (URM) & 44 & $67.7^{\mathrm{a}}$ \\
Reference given & 52 & $80.0^{\mathrm{a}}$ \\
Website URL given & 42 & $64.6^{\mathrm{a}}$ \\
Referred to its manuscript preparation section & 39 & $60.0^{\mathrm{a}}$ \\
\hline
\end{tabular}

ICMJE: International Committee of Medical Journal Editors.

$\mathrm{N}$ : number of journals.

URM: Uniform Requirements for Manuscripts submitted to biomedical journals.

${ }^{\mathrm{a}}$ The proportion among those that mentioned the ICMJE Recommendations.

Appendix Table 5. Main related policies in instructions for authors $(n=109)$.

\begin{tabular}{llcl}
\hline & \multicolumn{3}{c}{$\mathbf{N}(\%)$} \\
\cline { 2 - 4 } & Not & Recommended & Required \\
& mentioned & & \\
\hline Trial Registration & $69(63.3)$ & $20(18.3)$ & $20(18.3)$ \\
Funding Source & $19(17.4)$ & $43(39.4)$ & $47(43.1)$ \\
\hline
\end{tabular}

$\mathrm{N}$ : number of journals.

Appendix Table 6. Information regarding online reporting guideline libraries in instructions for authors $(n=109)$.

\begin{tabular}{llcc}
\hline Library & Category & N & $\%$ \\
\hline EQUATOR Network & Not mentioned & 98 & 89.9 \\
& Mentioned & 11 & 10.1 \\
& Reference given & 9 & $81.8^{\text {a }}$ \\
& Website URL given & 9 & $81.8^{\text {a }}$ \\
MIBBI Portal & Not mentioned & 107 & 98.2 \\
& Mentioned & 2 & 1.8 \\
& Reference given & 2 & $100.0^{\text {a }}$ \\
& Website URL given & 2 & $100.0^{\text {a }}$ \\
\hline
\end{tabular}

$\mathrm{N}$ : number of journals.

EQUATOR: Enhancing the QUAlity and Transparency Of health Research.

MIBBI: Minimum Information for Biological and Biomedical Investigations.

${ }^{\mathrm{a}}$ The proportion among those mentioned the corresponding library. 
Appendix Table 7. Any mention of reporting guidelines (RGs) and relevant policies in instructions for reviewers $(n=9)$.

\begin{tabular}{|c|c|c|c|}
\hline & Category & $\mathbf{N}$ & $\%$ \\
\hline \multirow[t]{2}{*}{ RGs } & Any mention & 3 & 33.3 \\
\hline & Only general term " $R G$ " mentioned ${ }^{\text {a }}$ & 2 & 22.2 \\
\hline \multirow[t]{4}{*}{ ICMJE Recommendations } & Mentioned $^{\mathbf{b}}$ & 1 & 11.1 \\
\hline & Reference given & 1 & $100.0^{c}$ \\
\hline & Website URL given & 1 & $100.0^{c}$ \\
\hline & Referred to its MS preparation section & 0 & $0.0^{c}$ \\
\hline \multirow[t]{3}{*}{ EQUATOR Network } & Mentioned $^{\mathbf{b}}$ & 1 & 11.1 \\
\hline & Reference given & 1 & $100.0^{c}$ \\
\hline & Website URL given & 1 & $100.0^{\mathrm{c}}$ \\
\hline \multirow[t]{3}{*}{ MIBBI Portal } & Mentioned $^{\mathbf{b}}$ & 1 & 11.1 \\
\hline & Reference given & 1 & $100.0^{c}$ \\
\hline & Website URL given & 1 & $100.0^{c}$ \\
\hline
\end{tabular}

$\mathrm{N}$ : number of journals.

${ }^{a}$ No specific reporting guideline was mentioned.

${ }^{b}$ All mentioned in the instruction of one journal (Prog Orthod).

${ }^{\mathrm{c}}$ The proportion among those mentioned the corresponding guideline/library.

Appendix Table 8. Endorsement of each specific reporting guideline (RG) in instructions for reviewers $(n=9)$.

\begin{tabular}{|c|c|c|c|c|c|c|c|}
\hline \multirow[b]{2}{*}{$\mathbf{R G}^{\mathrm{a}}$} & \multicolumn{2}{|c|}{ Mentioned (\%) } & \multicolumn{3}{|c|}{ Level of Endorsement (\%) } & \multicolumn{2}{|c|}{ Reference (\%) ${ }^{c}$} \\
\hline & No & Yes & $\begin{array}{l}\text { Recom- } \\
\text { mended }\end{array}$ & Required & $\begin{array}{l}\text { Submission } \\
\text { Required }^{\text {b }}\end{array}$ & $\begin{array}{c}\text { Reference } \\
\text { given }\end{array}$ & $\begin{array}{l}\text { Website } \\
\text { URL given }\end{array}$ \\
\hline CONSORT & $8(88.9)$ & $1(11.1)$ & $1(11.1)$ & $0(0.0)$ & $0(0.0)$ & $1(100.0)$ & $1(100.0)$ \\
\hline PRISMA & $8(88.9)$ & $1(11.1)$ & $1(11.1)$ & $0(0.0)$ & $0(0.0)$ & $1(100.0)$ & $1(100.0)$ \\
\hline MOOSE & 8 (88.9) & $1(11.1)$ & $1(11.1)$ & $0(0.0)$ & $0(0.0)$ & $1(100.0)$ & $1(100.0)$ \\
\hline STROBE & 8 (88.9) & $1(11.1)$ & $1(11.1)$ & $0(0.0)$ & $0(0.0)$ & $1(100.0)$ & $1(100.0)$ \\
\hline STARD & 8 (88.9) & $1(11.1)$ & $1(11.1)$ & $0(0.0)$ & $0(0.0)$ & $1(100.0)$ & $1(100.0)$ \\
\hline $\begin{array}{l}\text { Cochrane } \\
\text { guidelines }\end{array}$ & $8(88.9)$ & $1(11.1)$ & $1(11.1)$ & $0(0.0)$ & $0(0.0)$ & $1(100.0)$ & $1(100.0)$ \\
\hline $\begin{array}{l}{ }^{a} \text { All } m \\
\text { journ }\end{array}$ & $\begin{array}{l}\text { oned in } t \\
\text { whose in }\end{array}$ & $\begin{array}{l}\text { structio } \\
\text { tions fo }\end{array}$ & $\begin{array}{l}\text { he journ } \\
\text { wers we }\end{array}$ & $\begin{array}{l}\text { Prog Orthc } \\
\text { available. }\end{array}$ & d). No other & s mention & d for all nin \\
\hline
\end{tabular}


Appendix Table 9. Awareness of 19 specific RGs relevant to dental research among editors with previous knowledge of RGs ( $n=23)$.

\begin{tabular}{lcc}
\hline RG & $\mathbf{N}^{\mathrm{a}}$ & $\%^{\mathrm{a}}$ \\
\hline CONSORT & 21 & 91.3 \\
CONSORT extensions & & \\
$\quad$ for abstracts & 9 & 39.1 \\
$\quad$ for CRT & 4 & 17.4 \\
$\quad$ for noninferiority trials & 4 & 17.4 \\
$\quad$ for harms & 3 & 13.0 \\
$\quad$ for PRO & 7 & 30.4 \\
SPIRIT & 0 & 0.0 \\
PRISMA & 17 & 73.9 \\
PRISMA extensions & & \\
$\quad$ for abstracts & 6 & 26.1 \\
$\quad$ for protocols & 8 & 34.8 \\
MOOSE & 6 & 26.1 \\
STROBE & 14 & 60.9 \\
STARD & 6 & 26.1 \\
CARE & 8 & 34.8 \\
TREND & 0 & 0.0 \\
COREQ & 3 & 13.0 \\
ARRIVE & 5 & 21.7 \\
STREGA & 1 & 4.3 \\
STROBE-ME & 0 & 0.0 \\
\hline I & &
\end{tabular}

$\mathrm{N}$ : number of respondents.

${ }^{\text {a }}$ Numbers and percentages add up to more than 23 and $100 \%$ respectively since multiple RGs could be known by each respondent. 
Appendix Table 10. Sources where EICs learned about RGs ( $n=26)$.

\begin{tabular}{lcc}
\hline Source & $\mathbf{N}^{\mathbf{a}}$ & $\mathbf{\%}^{\mathbf{a}}$ \\
\hline Conference/workshop & 7 & 26.9 \\
Medical Literature & 6 & 23.1 \\
Experience as an author (e.g. submission) & 5 & 19.2 \\
Internet & 4 & 15.4 \\
Colleague & 4 & 15.4 \\
Publisher & 3 & 11.5 \\
Experience as an editor & 3 & 11.5 \\
Teaching experience & 3 & 11.5 \\
Organisation (e.g. EQUATOR, WAME) & 3 & 11.5 \\
University/Faculty & 2 & 7.7 \\
Funder & 1 & 3.8 \\
\hline
\end{tabular}

$\mathrm{N}$ : number of respondents.

${ }^{a}$ Numbers and percentages add up to more than 26 and 100\% respectively since multiple source could be provided by each respondent.

Appendix Table 11. RGs referred to in instructions to authors as reported by editors whose journals' instructions to authors mentioned RGs ( $n=17)$.

\begin{tabular}{lcc}
\hline RG & $\mathbf{N}^{\mathbf{a}}$ & $\mathbf{\%}^{\mathbf{a}}$ \\
\hline CONSORT & 12 & 75.0 \\
PRISMA & 10 & 58.8 \\
STROBE & 6 & 35.3 \\
MOOSE & 1 & 5.9 \\
STARD & 1 & 5.9 \\
CARE & 1 & 5.9 \\
ARRIVE & 1 & 5.9 \\
QUOROM $^{\mathbf{b}}$ & 1 & 5.9 \\
\hline
\end{tabular}

$\mathrm{N}$ : number of respondents.

a Numbers and percentages add up to more than 17 and $100 \%$ respectively since multiple RGs could be mentioned by each respondent's journal.

b Obsolete guideline replaced by PRISMA, endorsement of which thus inappropriate. 
Appendix Table 12. Reasons for referring to RGs in instructions to authors $(n=17)$.

\begin{tabular}{lcc}
\hline Reason & $\mathbf{N}^{\mathrm{a}}$ & $\mathbf{\%}^{\mathrm{a}}$ \\
\hline Standardize/improve/guide reporting & 11 & 64.7 \\
Improve quality of submissions/reports & 5 & 29.4 \\
Relevant to the journal content & 2 & 11.8 \\
Improve quality of research & 1 & 5.9 \\
To be same with other journals & 1 & 5.9 \\
Don't know & 1 & 5.9 \\
\hline
\end{tabular}

$\mathrm{N}$ : number of respondents.

${ }^{a}$ Numbers and percentages add up to more than 17 and 100\% respectively since multiple reasons could be provided by each respondent.

Appendix Table 13. Reasons for not referring to RGs in instructions to authors ( $n=15)$.

\begin{tabular}{|c|c|c|}
\hline Reason & $N^{a}$ & $\%^{a}$ \\
\hline $\begin{array}{l}\text { Instructions need to be updated and/or } \\
\text { will consider endorsing RGs }\end{array}$ & 8 & 53.3 \\
\hline Can guide the authors without RGs & 4 & 26.7 \\
\hline Not sure which of the RGs to endorse & 1 & 5.9 \\
\hline Irrelevant to the journal's content & 1 & 5.9 \\
\hline Journal has its own standards & 1 & 5.9 \\
\hline To be same with other journals & 1 & 5.9 \\
\hline $\begin{array}{l}\text { Authors know what scientific manuscripts } \\
\text { look like }\end{array}$ & 1 & 5.9 \\
\hline
\end{tabular}

$\mathrm{N}$ : number of respondents.

${ }^{a}$ Numbers and percentages add up to more than 15 and 100\% respectively since multiple reasons could be provided by each respondent. 
Appendix Table 14. Reasons for believing that RGs should be adopted by all refereed dental journals $(n=24)$.

\begin{tabular}{lcc}
\hline Reason & $\mathbf{N}^{\mathbf{a}}$ & $\mathbf{\%}^{\mathbf{a}}$ \\
\hline Improve/ensure quality/standardization & 16 & 66.7 \\
For the sake of research ethics and integrity & 5 & 20.8 \\
Better comparison between studies & 2 & 8.3 \\
Facilitate the mandate of RG usage & 1 & 4.2 \\
Avoid misuse of information & 1 & 4.2 \\
\hline
\end{tabular}

$\mathrm{N}$ : number of respondents.

${ }^{a}$ Numbers and percentages add up to more than 24 and $100 \%$ respectively since multiple reasons could be provided by each respondent.

Appendix Table 15. Factors preventing more widespread adoption of RGs by dental journals $(n=26)$.

\begin{tabular}{lcc}
\hline Factor & $\mathbf{N}^{\mathbf{a}}$ & $\mathbf{\%}^{\mathrm{a}}$ \\
\hline Lack of knowledge about RGs & 14 & 53.8 \\
Too much work for authors/editors & 4 & 15.4 \\
Not fully applicable to the field & 3 & 11.5 \\
Reluctance to scare/confuse authors & 3 & 11.5 \\
Poor quality of dental research & 3 & 11.5 \\
RGs are new and change takes time & 2 & 7.7 \\
Journals' need to publish & 2 & 7.7 \\
Lack of flexibility/enforceability & 2 & 7.7 \\
Resistance to change & 1 & 3.8 \\
Too many groups involved & 1 & 3.8 \\
Obsession on Impact Factor rather than standards & 1 & 3.8 \\
Following RGs may not result in good papers & 1 & 3.8 \\
Apathy & 1 & 3.8 \\
\hline
\end{tabular}

$\mathrm{N}$ : number of respondents.

${ }^{a}$ Numbers and percentages add up to more than 26 and 100\% respectively since multiple factors could be provided by each respondent. 
Appendix Table 16. Factors promoting more widespread adoption of RGs by dental journals $(n=30)$.

\begin{tabular}{|c|c|c|}
\hline Factor & $\mathbf{N}^{\mathrm{a}}$ & $\%^{a}$ \\
\hline More communications/information about RGs & 6 & 20.0 \\
\hline Education/training of all people involved & 6 & 20.0 \\
\hline Widespread adoption will occur with time & 5 & 16.7 \\
\hline $\begin{array}{l}\text { Remove from SCIE/PubMed journals without } \\
\text { clear policy of RG adoption }\end{array}$ & 3 & 10.0 \\
\hline Collaboration among dental journals & 2 & 6.7 \\
\hline $\begin{array}{l}\text { Change current performance indicators to rank } \\
\text { journals by quality of papers not citation }\end{array}$ & 2 & 6.7 \\
\hline Promote RG usage in instructions to authors & 2 & 6.7 \\
\hline $\begin{array}{l}\text { Recommendations from major } \\
\text { journals/publishers in the field }\end{array}$ & 2 & 6.7 \\
\hline Recognition of the importance of RGs & 2 & 6.7 \\
\hline Distribution of RGs to all journals & 1 & 3.3 \\
\hline $\begin{array}{l}\text { More and more submissions that do not adhere } \\
\text { to scientific format }\end{array}$ & 1 & 3.3 \\
\hline Widespread adoption is not needed & 1 & 3.3 \\
\hline
\end{tabular}

$\mathrm{N}$ : number of respondents.

${ }^{a}$ Numbers and percentages add up to more than 30 and $100 \%$ respectively since multiple factors could be provided by each respondent. 
Appendix Table 17. The best ways to disseminate information on RGs to dental journal editors $(n=32)$.

\begin{tabular}{lcc}
\hline Factor & $\mathbf{N}^{\mathbf{a}}$ & $\mathbf{\%}^{\mathbf{a}}$ \\
\hline Emails & 13 & 40.6 \\
Conferences/workshops (e.g. IADR meetings) & 5 & 15.6 \\
Online training/materials & 5 & 15.6 \\
Through organizations for dental journal editors & 4 & 12.5 \\
(e.g. the American Association of Dental Editors \& & & \\
Journalists) & & \\
Through the EQUATOR Network & 2 & 6.3 \\
Through publishers & 2 & 6.3 \\
A summary of selected RGs and relevant resources & 2 & 6.3 \\
Standardized texts by a team of experts to be used & 1 & 3.1 \\
$\quad$ on journals' websites & & \\
Quality assessment of published articles & 1 & 3.1 \\
Through Editors-in-Chief & 1 & 3.1 \\
All possible methods & 1 & 3.1 \\
\hline
\end{tabular}

$\mathrm{N}$ : number of respondents.

${ }^{a}$ Numbers and percentages add up to more than 32 and $100 \%$ respectively since multiple methods could be provided by each respondent. 
Appendix Figure 1. Flow diagram for journal selection.

\section{Journals identified through electronic searches:}

NLM Catalog (163), JCR (83)

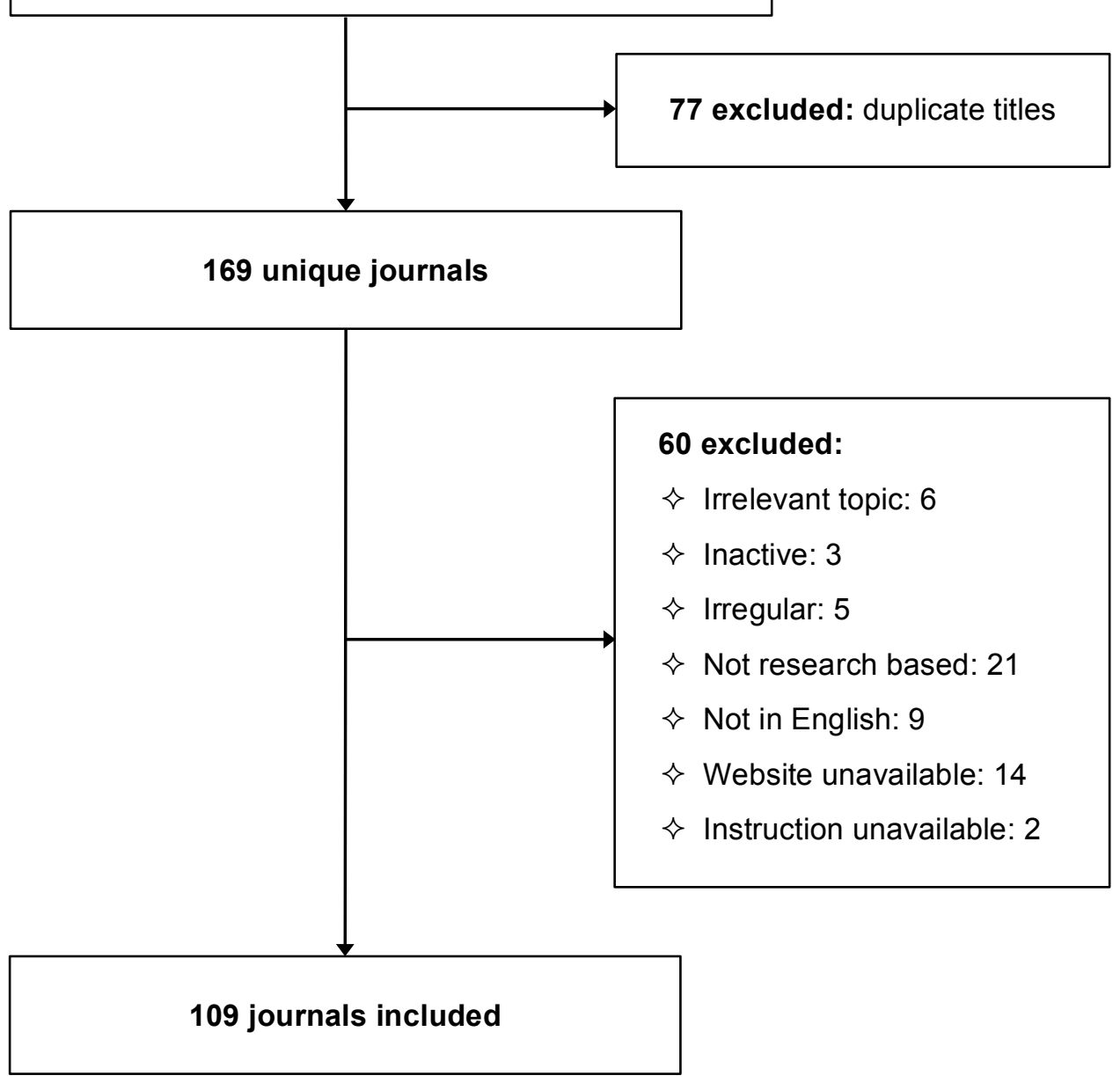




\section{References}

Beller EM, Glasziou PP, Altman DG, Hopewell S, Bastian H, Chalmers I, Gotzsche PC, Lasserson T, Tovey D, Group PfA. 2013. Prisma for abstracts: Reporting systematic reviews in journal and conference abstracts. PLoS Med. 10(4):e1001419.

Bossuyt PM, Reitsma JB, Bruns DE, Gatsonis CA, Glasziou PP, Irwig L, Lijmer JG, Moher D, Rennie D, de Vet HC et al. 2015. Stard 2015: An updated list of essential items for reporting diagnostic accuracy studies. BMJ. 351:h5527.

Calvert M, Blazeby J, Altman DG, Revicki DA, Moher D, Brundage MD, Group CP. 2013. Reporting of patient-reported outcomes in randomized trials: The consort pro extension. JAMA. 309(8):814-822.

Campbell MK, Piaggio G, Elbourne DR, Altman DG, Group C. 2012. Consort 2010 statement: Extension to cluster randomised trials. BMJ. 345:e5661.

Chan AW, Tetzlaff JM, Altman DG, Laupacis A, Gotzsche PC, Krleza-Jeric K, Hrobjartsson A, Mann H, Dickersin K, Berlin JA et al. 2013. Spirit 2013 statement: Defining standard protocol items for clinical trials. Ann Intern Med. 158(3):200-207.

Des Jarlais DC, Lyles C, Crepaz N, Group T. 2004. Improving the reporting quality of nonrandomized evaluations of behavioral and public health interventions: The trend statement. Am J Public Health. 94(3):361-366.

Faggion CM. 2011. Policies of dental journals for reporting and monitoring authorship and contributorship. Br Dent J. 211(5):223-227.

Fuller T, Pearson M, Peters J, Anderson R. 2015. What affects authors' and editors' use of reporting guidelines? Findings from an online survey and qualitative interviews. PLoS One. 10(4):e0121585.

Gagnier JJ, Kienle G, Altman DG, Moher D, Sox H, Riley D, Group C. 2014. The care guidelines: Consensus-based clinical case report guideline development. J Clin Epidemiol. 67(1):46-51.

Gallo V, Egger M, McCormack V, Farmer PB, Ioannidis JP, Kirsch-Volders M, Matullo G, Phillips DH, Schoket B, Stromberg U et al. 2011. Strengthening the reporting of observational studies in epidemiology--molecular epidemiology (strobe-me): An extension of the strobe statement. PLoS Med. 8(10):e1001117.

Grindlay DJ, Dean RS, Christopher MM, Brennan ML. 2014. A survey of the awareness, knowledge, policies and views of veterinary journal editors-in-chief on reporting guidelines for publication of research. BMC Vet Res. 10:10. 
Hirst A, Altman DG. 2012. Are peer reviewers encouraged to use reporting guidelines? A survey of 116 health research journals. PLoS One. 7(4):e35621.

Hopewell S, Altman DG, Moher D, Schulz KF. 2008a. Endorsement of the consort statement by high impact factor medical journals: A survey of journal editors and journal 'instructions to authors'. Trials. 9:20.

Hopewell S, Clarke M, Moher D, Wager E, Middleton P, Altman DG, Schulz KF, Group C. 2008b. Consort for reporting randomized controlled trials in journal and conference abstracts: Explanation and elaboration. PLoS Med. 5(1):e20.

Ioannidis JP, Evans SJ, Gotzsche PC, O'Neill RT, Altman DG, Schulz K, Moher D, Group C. 2004. Better reporting of harms in randomized trials: An extension of the consort statement. Ann Intern Med. 141(10):781-788.

Kilkenny C, Browne WJ, Cuthill IC, Emerson M, Altman DG. 2010. Improving bioscience research reporting: The arrive guidelines for reporting animal research. PLoS Biol. 8(6):e1000412.

Knuppel H, Metz C, Meerpohl JJ, Strech D. 2013. How psychiatry journals support the unbiased translation of clinical research. A cross-sectional study of editorial policies. PLoS One. 8(10):e75995.

Kunath F, Grobe HR, Rucker G, Engehausen D, Antes G, Wullich B, Meerpohl JJ. 2012. Do journals publishing in the field of urology endorse reporting guidelines? A survey of author instructions. Urol Int. 88(1):54-59.

Little J, Higgins JP, Ioannidis JP, Moher D, Gagnon F, von Elm E, Khoury MJ, Cohen B, Davey-Smith G, Grimshaw J et al. 2009. Strengthening the reporting of genetic association studies (strega): An extension of the strobe statement. PLoS Med. 6(2):e22.

Meerpohl JJ, Wolff RF, Niemeyer CM, Antes G, von Elm E. 2010. Editorial policies of pediatric journals: Survey of instructions for authors. Arch Pediatr Adolesc Med. 164(3):268-272.

Moher D, Hopewell S, Schulz KF, Montori V, Gotzsche PC, Devereaux PJ, Elbourne D, Egger M, Altman DG. 2010. Consort 2010 explanation and elaboration: Updated guidelines for reporting parallel group randomised trials. BMJ. 340:c869.

Moher D, Liberati A, Tetzlaff J, Altman DG, Group P. 2009. Preferred reporting items for systematic reviews and meta-analyses: The prisma statement. PLoS Med. 6(7):e1000097.

Piaggio G, Elbourne DR, Pocock SJ, Evans SJ, Altman DG, Group C. 2012. Reporting of noninferiority and equivalence randomized trials: Extension of the consort 2010 
statement. JAMA. 308(24):2594-2604.

Shamseer L, Moher D, Clarke M, Ghersi D, Liberati A, Petticrew M, Shekelle P, Stewart LA, Group P-P. 2015. Preferred reporting items for systematic review and meta-analysis protocols (prisma-p) 2015: Elaboration and explanation. BMJ. 349:g7647.

Smail-Faugeron V, Fron-Chabouis H, Durieux P. 2015. Clinical trial registration in oral health journals. J Dent Res. 94(3 Suppl):8S-13S.

Stroup DF, Berlin JA, Morton SC, Olkin I, Williamson GD, Rennie D, Moher D, Becker BJ, Sipe TA, Thacker SB. 2000. Meta-analysis of observational studies in epidemiology: A proposal for reporting. Meta-analysis of observational studies in epidemiology (moose) group. JAMA. 283(15):2008-2012.

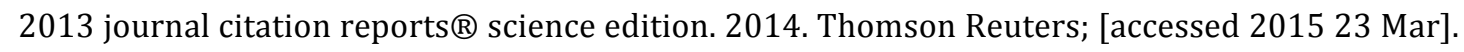
https://jcr.incites.thomsonreuters.com/JCRJournalHomeAction.action.

Tong A, Sainsbury P, Craig J. 2007. Consolidated criteria for reporting qualitative research (coreq): A 32-item checklist for interviews and focus groups. Int J Qual Health Care. 19(6):349-357.

Vandenbroucke JP, von Elm E, Altman DG, Gotzsche PC, Mulrow CD, Pocock SJ, Poole C, Schlesselman JJ, Egger M, Initiative S. 2007. Strengthening the reporting of observational studies in epidemiology (strobe): Explanation and elaboration. PLoS Med. 4(10):e297. 